\title{
A Unified Elastoplastic Model of Unsaturated Soils Considering Capillary Hysteresis
}

\author{
Tiantian Ma, ${ }^{1}$ Changfu Wei, ${ }^{1,2}$ Pan Chen, ${ }^{1}$ Huihui Tian, ${ }^{1}$ and De'an Sun ${ }^{3}$ \\ ${ }^{1}$ State Key Laboratory of Geomechanics and Geotechnical Engineering, Institute of Rock and Soil Mechanics, \\ Chinese Academy of Sciences, Xiaohongshan, Wuchang, Wuhan, Hubei 430071, China \\ ${ }^{2}$ College of Civil and Architectural Engineering, Guilin University of Technology, Guilin, Guangxi 541004, China \\ ${ }^{3}$ Department of Civil Engineering, Shanghai University, Shanghai 200072, China
}

Correspondence should be addressed to Changfu Wei; cfwei@whrsm.ac.cn

Received 14 May 2013; Accepted 26 July 2013

Academic Editor: Pengcheng Fu

Copyright (C) 2013 Tiantian Ma et al. This is an open access article distributed under the Creative Commons Attribution License, which permits unrestricted use, distribution, and reproduction in any medium, provided the original work is properly cited.

Unlike its saturated counterparts, the mechanical behavior of an unsaturated soil depends not only upon its stress history but also upon its hydraulic history. In this paper, a soil-water characteristic relationship which is capable of describing the effect of capillary hysteresis is introduced to characterize the influence of hydraulic history on the skeletal deformation. The capillary hysteresis is viewed as a phenomenon associated with the internal structural rearrangements in unsaturated soils, which can be characterized by using a set of internal state variables. It is shown that both capillary hysteresis and plastic deformation can be consistently addressed in a unified theoretical framework. Within this context, a constitutive model of unsaturated soils is developed by generalizing the modified Cam-Clay model. A hardening function is introduced, in which both the matric suction and the degree of saturation are explicitly included as hardening variables, so that the effect of hydraulic history on the mechanical response can be properly addressed. The proposed model is capable of capturing the main features of the unsaturated soil behavior. The new model has a hierarchical structure, and, depending upon application, it can describe the stress-strain relation and the soil-water characteristics in a coupled or uncoupled manner.

\section{Introduction}

Occurrence of geohazards is usually related to the failure of unsaturated soils induced by intensive precipitation or variation of the underground water table. Traditionally, in the analysis of such problems, the mechanical and hydraulic properties of unsaturated soils are considered in an uncoupled or partially coupled manner. However, sufficient experimental evidence $[1,2]$ shows that there exists complicated coupling effect between deformation and seepage processes in unsaturated soils. The seepage process can influence the mechanical properties of soils; for instance, repeated dryingwetting cycles can change the soil strength [3]; skeletal deformation can change the water-retention characteristics of unsaturated soils, which in turn influences the seepage process [3]. Hence, in analyzing unsaturated soil problems, it is crucial to properly characterize the coupling effect of seepage, deformation, and failure in unsaturated soils with arbitrary variation of water content. To address such an issue, a constitutive model must be developed which can effectively describe both the stress-strain relation and soil-water characteristics in a unified and coupled manner.

The first milestone for comprehensive unsaturated soil modeling should be attributed to Alonso et al. [4], who have developed the Barcelona Basic Model (BBM) by extending the modified Cam-Clay model of saturated soils. In the BBM model, two independent stress variables are adopted, and the so-called loading-collapse (LC) yield curve is introduced to express the hardening effect of matric suction on the preconsolidation pressure. In addition, another yield surface, namely, SI, is employed to describe the plastic yielding of the degree of saturation. The BBM model was experimentally validated by Wheeler and Sivakumar [5], based on a series of isotropic compression and triaxial tests on unsaturated soils under suction-controlled conditions. Although the BBM model can capture the main features of unsaturated soils, 
the mechanical and hydraulic behaviors are addressed in an uncoupled way. Wheeler and Sivakumar [5] have pointed that uncoupled models cannot effectively simulate the variation of the degree of saturation during shearing under constant matric suction, so that they are incapable of describing the mechanical behavior and water retention characteristics of unsaturated soils under undrained conditions.

To resolve these issues, Nuth et al. [6], Sun and Li [7], and Sheng et al. [8] introduced a Bishop's type effective stress instead of net stress as an independent stress variable. These models adopt LC yield curve to describe the wettinginduced collapse phenomenon under various stress states of unsaturated soils. D'Onza et al. [9] presented research work undertaken by seven universities to benchmark different approaches to modeling the behavior of unsaturated soils. Such models consider the effect of matric suction on the yield pressure only and ignore the effect of the degree of saturation.

Based on experimental results, Wheeler et al. [10] have concluded that the degree of saturation has a significant influence on the stress-strain relation. They have suggested that cyclic soil-water characteristic function should be introduced into the elastoplastic constitutive model of unsaturated soils, to describe the influence of the nonmonotonic variation in water content on the skeletal deformation.

An LC curve is one of the key components in the BBMstyle models $[1,4,5,11,12]$, reflecting the hardening effect of matric suction on unsaturated soils. It has been recognized [10] that the models with an LC yield surface have the following limitations. (1) They are insufficient in describing the soil response when the water content varies in a nonmonotonic way. In the vicinity of the transition region, when the matric suction is lower than the air entry value, the soil is fully saturated during a drying process, whereas the soil shows apparent unsaturated behavior during wetting. This phenomenon cannot be described by using an LC curve; (2) LC curve predicts the increase of the yield stress with matric suction, without considering the influence of the degree of saturation; (3) at the same matric suction, the mechanical properties of an unsaturated soil can be different due to the different hydraulic histories which the soil has experienced.

The preconsolidation pressure is a key variable, by which the hardening effect of capillarity can be taken into account in an unsaturated soil constitutive model [13]. Two approaches have been proposed to considering the hardening effect of capillarity. Khalili et al. [14] and Tamagnini [15] proposed a hardening function in which the preconsolidation pressure is multiplied by a function of matric suction. On the other hand, Jommi [16] and Li [17] believed that the matric suction should have an additive effect on the strain hardening, and thus the hardening effects of the matric suction and the volumetric deformation should be considered in an additive way. Noticeably, neither of these two approaches considers the contribution of the matric suction and the degree of saturation simultaneously, and thus neither one can effectively address the effect of hydraulic histories.

One of major differences between a saturated soil and its unsaturated counterpart resides in the fact that the mechanical behavior of the unsaturated soil depends not only upon its stress history but also upon its hydraulic history.
The hydraulic history can be very well addressed by using a soil-water characteristic relationship, which is capable of describing the capillary hysteresis of the unsaturated soil under an arbitrary wetting/drying path $[18,19]$. There are several kinds of hysteretic models for the soil-water characteristics, including empirical models, the domain model [20], the rational extrapolated model [21], and the bounding surface model [19], respectively. Recently, Wei and Dewoolkar [18] identified a link between the capillary hysteresis and an intrinsic dissipation process in unsaturated soil, and developed an internal-variable model of capillary hysteresis, allowing the capillary hysteresis and skeletal deformation to be simulated in a unified framework of elastoplastic theory. Although several constitutive models of unsaturated soils have addressed the effect of capillary hysteresis to a certain degree, they seldom consider the influence of deformation on the water retention characteristic. Miao et al. [22] studied the influence of soil density on the soil-water characteristic curve, suggesting that skeletal compression has significant effect on the soil-water characteristics. Gallipoli et al. [23] have performed experiments and developed the relationship between volumetric strain and the parameters of van Genuchten model [24].

Li [25] has discussed the work-energy-dissipation relations for unsaturated soils, based on the principles of thermodynamics. In his paper, Li [25] has clearly displayed the coupling effect among three phases and developed an elastoplastic framework for coupling the mechanical and hydraulic behavior of unsaturated soils, under which a constitutive model was developed under the triaxial stress state [17]. This framework provides a solid base for developing the constitutive model of unsaturated soils.

In this paper, a new hardening function is proposed, in which the matric suction and the degree of saturation as well as plastic volumetric strain are simultaneously introduced to represent the hardening effect. Based on Li's framework [25], a constitutive model is developed, which can simulate plastic deformation and capillary hysteresis in a coupled and hierarchical manner. If the coupled effect of skeletal deformation and capillary hysteresis is ignored, the new model degenerates into two independent models of unsaturated soils, namely, the stress-strain relationship and the soil-water characteristic curve. When the deformation of soil is excluded, the model ends up with a model for the soil-water characteristics. When the soil becomes fully saturated, the new model can transit smoothly to the modified Cam-Clay (MCC) model.

\section{Theoretical Formulation}

2.1. Stress State Variables. The displacement work of unsaturated soil can be expressed as [26]

$$
\begin{aligned}
W= & \left\{\sigma_{i j}-\left[S_{r} u_{w}+\left(1-S_{r}\right) u_{a}\right] \delta_{i j}\right\} \dot{\varepsilon}_{i j} \\
& -n s_{c} \dot{S}_{r}+n\left(1-S_{r}\right) u_{a} \frac{\dot{\rho}_{a}}{\rho_{a}}
\end{aligned}
$$

where $\sigma_{i j}$ is the total stress tensor; $S_{r}$ is the degree of saturation; $u_{a}$ and $u_{w}$ are the pore air pressure and pore water 


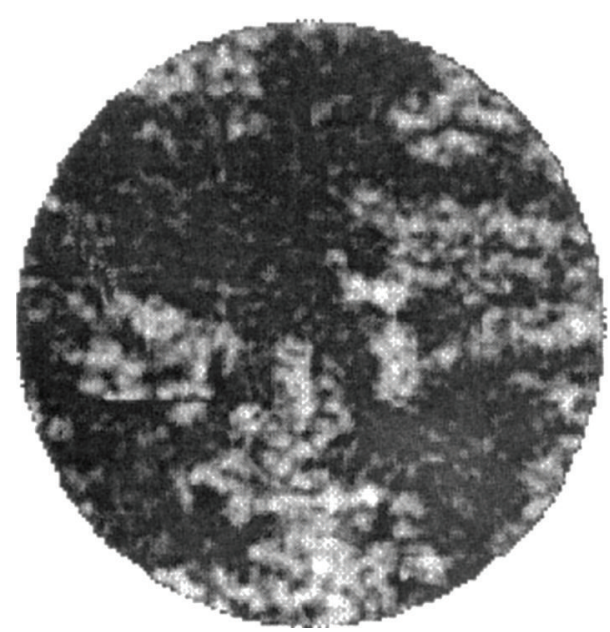

(a)

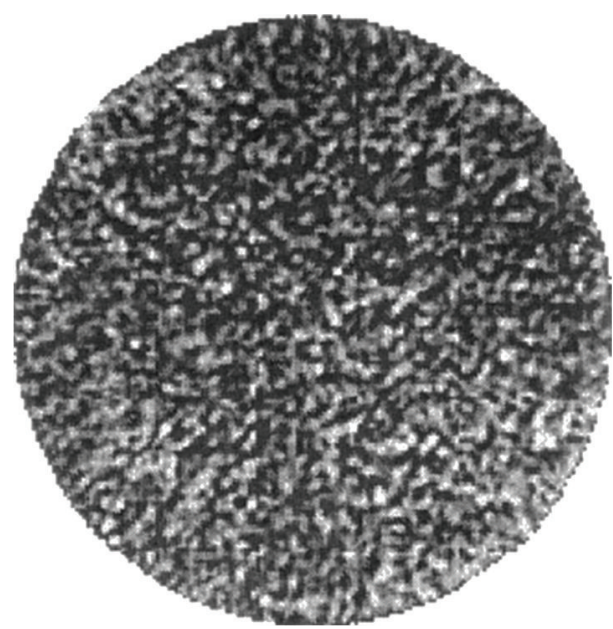

(b)

Figure 1: CT images of moisture distribution in the unsaturated Estaillades limestone at saturation of 92\%: (a) prepared by drying; (b) prepared by wetting (after Cadoret et al. (1998) [31]).

pressure, respectively; $\delta_{i j}$ is the unit tensor; $s_{c}$ is the matric suction, that is, $s_{c}=u_{a}-u_{w} ; \varepsilon_{i j}$ is the infinitesimal strain tensor; $n$ is the porosity; $\rho_{a}$ is the density of pore air. If the work of air compression is neglected, the third item in the right-hand side disappears, and

$$
W=\sigma_{i j}^{\prime} \dot{\varepsilon}_{i j}-n s_{c} \dot{S}_{r}
$$

where $\sigma_{i j}^{\prime}$ is the average skeleton stress tensor [16], defined by

$$
\sigma_{i j}^{\prime}=\left(\sigma_{i j}-u_{a} \delta_{i j}\right)+S_{r}\left(u_{a}-u_{w}\right) \delta_{i j}
$$

At the triaxial stress state,

$$
\begin{gathered}
p^{\prime}=\frac{\sigma_{i i}^{\prime}}{3}=\left(p-u_{a}\right)+S_{r}\left(u_{a}-u_{w}\right), \\
q=\sigma_{1}^{\prime}-\sigma_{3}^{\prime},
\end{gathered}
$$

where $p^{\prime}$ and $q$ are the mean and deviatoric skeleton stresses, respectively; $p$ is the mean total stress. $\sigma_{i j}^{\prime}$ is defined by (3) and simply the Bishop's equation for the "effective" stress of unsaturated soils [27], with parameter $\chi$ being equal to the degree of saturation $S_{r}$.

According to (2), Houlsby [26] proposed that the constitutive behavior of unsaturated soils should be described using stress state variables $\left(\sigma_{i j}^{\prime}, n s_{c}\right)$, which are work conjugated to strain variables $\left(\varepsilon_{i j}, S_{r}\right)$. Although this proposition is widely introduced in modeling unsaturated soil behavior, it has been recently criticized for choosing parameter $\chi$ as the degree of saturation $S_{r}$, for example, [14, 28-30]. Based on the equivalency of shear strength (Mohr-Coulomb's type), Khalili and Zargarbashi [28] performed direct experiments to measure parameter $\chi$, confirming that $\chi$ is not equal to $S_{r}$ and depends upon the hydraulic history of the soil.

To reconcile the above-mentioned inconsistency and considering the difficulty and uncertainty in measuring parameter $\chi$, we propose herein that (1), in a general framework for modeling the constitutive behavior of unsaturated soils, the stress variables must be properly conjugated to the strain variables; that is, a robust constitutive model must be thermodynamically consistent, and (2) the dependence of "effective" stress parameter on hydraulic history is constitutive in nature, and the hydraulic hysteretic effect can be simulated in a general constitutive framework. Hence, we suggest that stress variables $\left(\sigma_{i j}^{\prime}, n s_{c}\right)$ should be adopted in the constitutive modeling of unsaturated soils. Because porosity $n$ is practically independent of the hydraulic path which the soil experienced, for convenience, $s_{c}$ instead of $n s_{c}$ will be used in describing the hydraulic history and the effect of unsaturation. In the following, we will prove that the effect of hydraulic history can indeed be effectively addressed in a constitutive model, which uses $\left(\sigma_{i j}^{\prime}, s_{c}\right)$ as stress state variables.

2.2. Hydraulic-History Dependence of Unsaturated Soils. One of salient features of unsaturated soil behavior is its dependence on the hydraulic history. At the same degree of saturation, the moisture distribution in the pore space of a soil can be different, depending upon the wetting/drying history that the soil experienced. Figure 1 illustrates the CT images of the moisture distributions in two limestone samples with the same matrix and the same saturation [31]. It can be seen that the moisture distributions in the two samples are significantly different, and the moisture distribution is more uniform in the sample with a wetting path than that in the sample with a drying path. Remarkably, the nonuniformity of moisture distribution can be induced by the hydraulic history even in a soil with apparently homogeneous solid matrix [32]. Therefore, local heterogeneity (or local structures) can be created in an unsaturated soil merely by its wetting/drying history.

As a consequence, at the same saturation or matric suction, the mechanical response of an unsaturated soil can 
be different, depending upon the wetting/drying history of the soil. Indeed, it has been very well recognized in the community of geophysics [36-38] that the phase velocity of the first compression wave in a partially saturated geomaterial depends strongly upon its hydraulic history, implying that the stiffness of the material depends upon its wetting/drying history. Generally, at the same saturation, a geomaterial with a drying history is stiffer than that with a wetting history.

We suggest that the phenomenon of capillary hysteresis in unsaturated soils can be tightly related to the local heterogeneity of moisture distribution (i.e., local structures). At the same saturation, the matric suction could be different if the moisture distribution pattern in the pore space is different. Hence, capillary hysteresis can be viewed as a process of local structural rearrangements related to the change of moisture distribution in unsaturated soils.

As such, the role of a soil-water characteristic curve (SWCC) in modeling an unsaturated soil is two-folded: on the one hand, the SWCC describes the capillary hysteresis of the soil during wetting/drying cycles, and, on the other hand, it represents the effect of hydraulic history on the skeletal deformation, if the SWCC can be properly implemented in the stress-strain relationship of the soil.

2.3. Coupling of Dissipative Processes. In modeling the constitutive behavior of unsaturated soils, two coupled irreversible processes (or phenomena) have to be properly addressed, namely, plastic skeletal deformation and capillary hysteresis. Based on the internal-variable theory of plasticity, such irreversible processes are associated with the rearrangements of internal structures in unsaturated soils, which can be characterized by a series of internal state variables (e.g., $[18,39]$ ). $\mathrm{Li}$ [25] proposed that the energy dissipation associated with plastic deformation and capillary hysteresis in an unsaturated soil can be expressed as

$$
\zeta_{i} \delta \xi_{i}=\zeta_{i}^{s} \delta \xi_{i}^{s}+\zeta_{i}^{f} \delta \xi_{i}^{f},
$$

where $\xi_{i}(i=1,2, \ldots, N)$ is a set of internal state variables, used to characterize the pattern of the internal structures in the soils; $\zeta_{i}$ is the thermodynamic forces conjugated with $\xi_{i} ; \delta \xi_{i}$ is the evolution of an internal variable. It is clear from (5) that the total dissipation is additively decomposed into two parts, $\zeta_{i}^{s} \delta \xi_{i}^{s}$ and $\zeta_{i}^{f} \delta \xi_{i}^{f}$, which represent the incremental dissipations in the soil skeleton and the pore fluids, respectively. $\delta \xi_{i}^{\alpha}(\alpha=s, f)$ represents the variation of the internal variables of $\alpha$-phase; $\zeta_{i}^{\alpha}$ is the thermodynamic force conjugated with $\xi_{i}^{\alpha}$ and is a function of state variables and structural variation history. Both $\zeta_{i}^{\alpha}$ and $\delta \xi_{i}^{\alpha}$ are related to the pattern of internal structural rearrangements.

The structural rearrangements of unsaturated soils can be symbolically expressed as [25]

$$
H=H\left(H_{s}, H_{f}\right),
$$

where $H_{s}$ and $H_{f}$ represent the patterns of the structural rearrangements associated with plastic deformation in the solid skeleton and capillary hysteresis in the pore fluid, respectively. To account for the interaction between these two dissipation processes, $H_{s}$ and $H_{f}$ are further expressed as

$$
\begin{aligned}
H_{s} & =H_{s}\left[H_{s}^{\prime}, H_{s}^{\prime \prime}\left(H_{s}^{\prime}, s_{c}, S_{r}\right)\right], \\
H_{f} & =H_{f}\left[H_{f}^{\prime}, H_{f}^{\prime \prime}\left(H_{f}^{\prime}, \boldsymbol{\sigma}^{\prime}, \boldsymbol{\varepsilon}\right)\right],
\end{aligned}
$$

where $H_{\alpha}^{\prime}$ and $H_{\alpha}^{\prime \prime}(\alpha=s, f)$ denote the intrinsic structural rearrangement and its interactive counterpart of phase $\alpha$, respectively. Clearly, $H_{\alpha}^{\prime \prime}$ accounts for the coupling effect. Particularly, $H_{s}^{\prime \prime}\left(H_{s}^{\prime}, s_{c}, S_{r}\right)$ represents the effect of hydraulic path on the pattern of the structural rearrangements in the solid skeleton, which implies that the extent that the hydraulic path influences the skeletal plastic deformation depends upon the intrinsic structural rearrangements of the skeleton. Similarly, $H_{f}^{\prime \prime}\left(H_{f}^{\prime}, \boldsymbol{\sigma}^{\prime}, \boldsymbol{\varepsilon}\right)$ denotes the influence of skeletal deformation on the dissipation related to capillary hysteresis in fluid phase, and the extent of the influence depends upon the intrinsic structural rearrangements, that is, the distribution pattern of the moisture in pores, of the pore water.

Clearly, the mechanical and water retention behaviors can be described in a unified theoretical framework. In this paper, an elastoplastic constitutive model of unsaturated soils coupling skeletal deformation and capillary hysteresis is developed based on such a framework.

2.4. Yielding and Hardening. The stress-strain relationship is developed by generalizing the modified Cam-Clay model [40], in which the yield function is given by

$$
f=q^{2}+M^{2} p^{\prime}\left(p^{\prime}-p_{c}\right),
$$

where $M$ is the slope of critical state line; $p_{c}$ is the preconsolidation pressure. At full saturation, $p_{c}$ is a function of plastic volumetric strain only; that is, $p_{c}=p_{c_{0}}\left(\varepsilon_{v}^{p}\right)$. According to the discussions in Section 2.3, under partially saturated conditions, $p_{c}$ depends upon matric suction and the degree of saturation as well as the plastic volumetric strain. It is suggested herein that, in general, one can assume

$$
p_{c}=p_{c_{0}}\left(\varepsilon_{v}^{p}\right) h\left(\varepsilon_{v}^{p}, S_{r}, s_{c}\right),
$$

where $h$ is a correction function, which accounts for the hardening effect of unsaturation. As discussed in the previous section, $h$ is assumed as a function of $s_{c}$ and $S_{r}$ as well as $\varepsilon_{v}^{p}$.

To derive an explicit expression for $h$, one first notes that (1), when the soil is fully saturated, the effect of capillarity on the hardening is vanishing; that is, $h=1.0$ when $S_{r}=100 \%$; (2) when the degree of saturation approaches its residual value $S_{r}^{\text {irr }}$, the water phase becomes discontinuous and occurs only as meniscus water rings at interparticle contacts or as thin film (contractile skin) surrounding the soil particles $[41,42]$. In this case, the effect of the degree of saturation on the hardening becomes trivial, and the effect of matric suction approaches to a stable value. In addition, with the increase of plastic volumetric strain, the soil tends to be stiffer, and effect of unsaturation on hardening wanes.

As discussed in Section 2.2, the hardening effect of unsaturation depends upon the hydraulic history that 


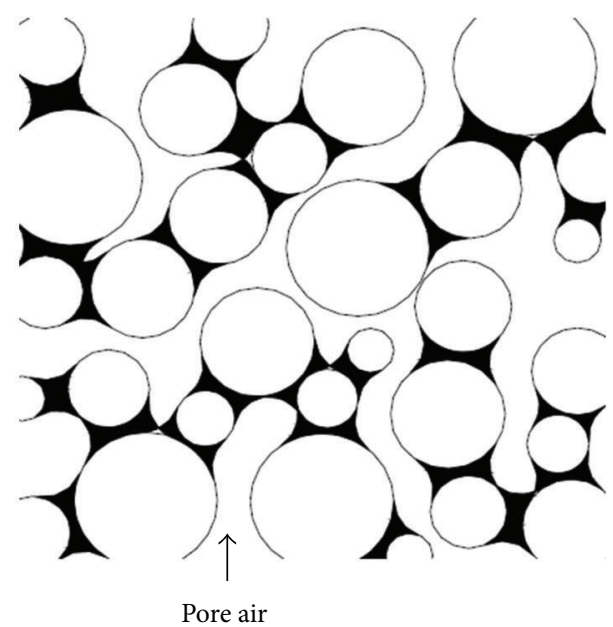

(a)

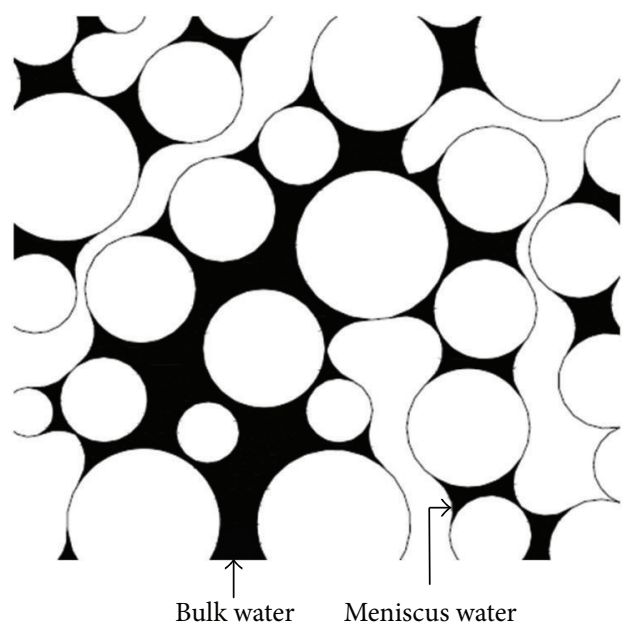

(b)

FIGURE 2: Effect of hydraulic history on the moisture distribution: (a) idealized moisture distribution pattern; (b) after several wetting-drying cycles (after Wheeler et al. (2003) [10]).

the soil experienced. To take into account such an effect, we first take a close inspection of the microscopic pattern of the moisture distribution in the pore space. As shown in Figure 2 [10], at the same matric suction, the distribution of moisture in an unsaturated soil sample can be different due to different hydraulic histories that the soil experienced. Figure 2(a) depicts an idealized moisture distribution pattern with specified matric suction, while Figure 2(b) represents the soil after certain wetting/drying cycles, at the same matric suction. Compared to the soil depicted in Figure 2(a), the soil shown in Figure 2(b) has higher saturation and a more heterogeneous structure. In the latter case, some regions in the soil are fully saturated, whereas the other regions remain relatively dry. The pore waters in the wet regions and dry regions influence the mechanical behavior of the soil in different ways. Namely, the negative pore water pressure in the wet regions contributes mainly to modification of the skeleton stress in a way as described by (3), whereas the pore water in the meniscus rings in the dry areas may have a stabilizing effect at the inter-particle contacts, due to the existence of surface tension (e.g., $[16,43]$ ).

The stabilizing effect of meniscus water rings has two contributions [44]: one is related to the contractile films at interfaces between the wetting phase and nonwetting phase, which can pull the particles together, producing a hardening effect on the mechanical behavior; the other is due to the additional normal force at inter-particle contacts induced by the negative pore water pressure in the meniscus water rings, which can decrease the possibility of slippage (plastic strain) at the inter-particle contacts. Clearly, the stabilizing effect of meniscus water rings has a direct influence on the yielding and hardening of unsaturated soils. At specified matric suction, the stabilizing effect of meniscus water rings may become stronger when the quantity of meniscus water rings increases. Because the quantity of meniscus water rings can be represented by the amount of pore air, we suggest that the hardening effect of unsaturation can be collectively characterized by using variable $\left(1-S_{r}\right) s_{c}$. Remarkably, at the specified matric suction, the value of $\left(1-S_{r}\right) s_{c}$ depends uniquely upon the pattern of moisture distribution in the pores, that is, upon the hydraulic history that the soil experienced.

Based on the above discussions, it is proposed herein that

$$
\begin{aligned}
& h\left(\varepsilon_{v}^{p}, S_{r}, s_{c}\right) \\
& \quad=r-(r-1) \exp \left\{-m\left\langle 1-\frac{\varepsilon_{v}^{p}}{\varepsilon_{v, \max }^{p}}\right\rangle \frac{\left(1-S_{r}\right) s_{c}}{\left(1-S_{r}^{\mathrm{irr}}\right)}\right\},
\end{aligned}
$$

where $r$ is a parameter which truncates the effect of high matric suction on the preconsolidation pressures, namely, $r=\left.h\right|_{s_{c} \rightarrow \infty} ; m$ is a factor characterizing the changing rate of preconsolidation pressure with the variation of $\left(1-S_{r}\right) s_{c}$; $\varepsilon_{v, \max }^{p}$ is the threshold value of plastic volumetric strain at which the effect of unsaturation becomes trivial; $S_{r}^{\text {irr }}$ is the residual degree of saturation; \langle\rangle is Macauley bracket, defined as $\langle x\rangle=x H(x)$, where $H(x)$ is Heaviside function.

A typical relation among variables $h, S_{r}$, and $s_{c}$ is schematically shown in Figure 3(a) in the three-dimensional space. Equation (10) describes the hardening surface as a function of $S_{r}$ and $s_{c}$, bounded by the dashed and solid lines representing the drying and wetting boundaries, respectively. The projections of the hardening surface on the two-dimensional plots are also shown in Figure 3(a), where on the $S_{r}: s_{c}$ plane the projection yields the SWCC curve with capillary hysteresis, on the $s_{c}: h$ plane it describes the effect of matric suction on the hardening, and on the $S_{r}: h$ plane it describes the effect of saturation on the hardening. Remarkably, $h$ increases with the decrease in saturation or increase in suction and approaches to a certain value when $S_{r} \rightarrow 0$ or $s_{c} \rightarrow+\infty$.

From the proposed hardening function, the effect of $S_{r}$ and $s_{c}$ on the preconsolidation pressure diminishes gradually with the increasing of $\varepsilon_{v}^{p}$. When $\varepsilon_{v}^{p}$ reaches the maximum $\varepsilon_{v, \text { max }}^{p}$, the influence of $S_{r}$ and $s_{c}$ on the preconsolidation 


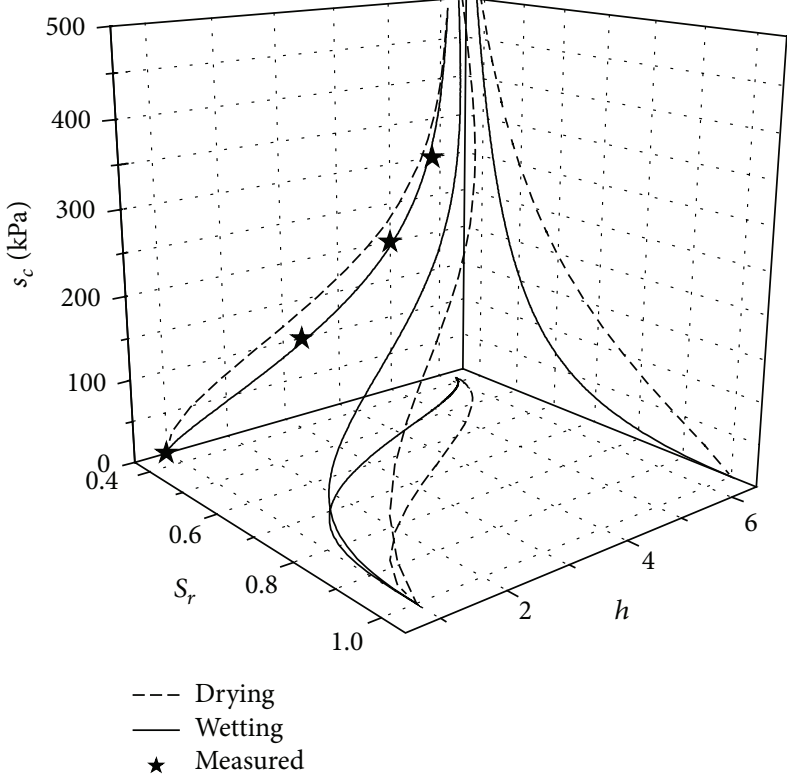

(a)

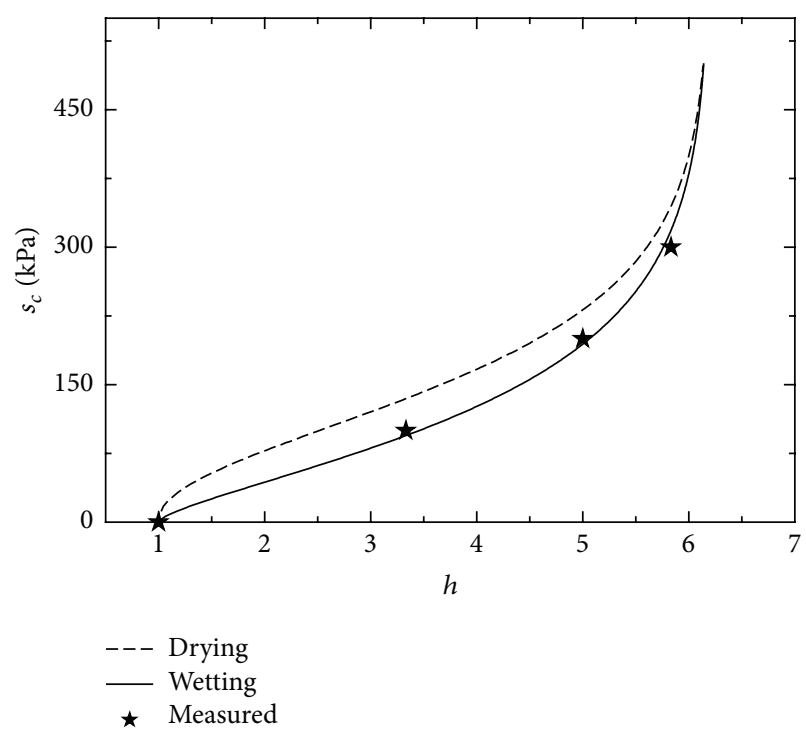

(b)

FIGURE 3: Relations among $h, s_{c}$, and $S_{r}$ : (a) three-dimensional view of the hardening surface; (b) projection of the hardening surface on the $s_{c}: h$ plane (data after Wheeler and Sivakumar (1995) [5]).

pressure disappears, implying that the soil is very dense and the capillary effect can be negligible. The above characteristics are consistent with the actual situation. The proposed function can transit from saturated state to unsaturated state smoothly, where both states can be described in a single framework. In addition, it can be numerically implemented in a straightforward way.

Figure 3(b) shows the projection of the hardening surface on the $s_{c}: h$ plane, revealing that at the same matric suction the value of $p_{c}$ for drying is consistently smaller than that for wetting, since at a specified matric suction the degree of saturation for drying is larger than that for wetting. The discrepancy diminishes when the matric suction increases. This typical feature of unsaturated soil behavior cannot be addressed by the existing elastoplastic constitutive frameworks formulated in terms of LC yield surface. The mathematical feature can be physically interpreted by considering that a lower degree of saturation implies a larger number of contact zones between the pore fluid menisci. It can be seen that the simulated hardening parameter $h$ agrees very well with the experimental data for the wetting path that are available in the literature [5].

2.5. Elastoplastic Stress-Strain Relation. Sufficient experimental results $[45,46]$ show that the influence of meniscus water rings on the shear strength parameters (i.e., $c^{\prime}$ and $\phi$ ) is negligible, provided that the strength line is plotted on the $p^{\prime}: q$ plane. Hence it is suggested herein that the critical state line of unsaturated soil is the same as that of its saturated counterpart, and the failure line is simply given by $q=M p^{\prime}$, where $M$ is independent of the matric suction or the degree of saturation.
As in the original modified Cam-Clay model, the increments of elastic volumetric strain and deviatoric strain are defined as

$$
d \varepsilon_{v}^{e}=\frac{\kappa d p^{\prime}}{v p^{\prime}}, \quad d \varepsilon_{q}^{e}=\frac{d q}{3 G}
$$

where $\kappa$ is the slope of the unloading-reloading line on the $v-\ln p^{\prime}$ plane of the soil under the fully saturated condition, $v$ is the specific volume $v=1+e, e$ the void ratio, and $G$ the shear modulus.

An associated flow rule is adopted herein: thus the plastic potential coincides with the yield function. The incremental plastic volumetric and deviatoric strains are given by

$$
d \varepsilon_{v}^{p}=d \lambda \frac{\partial f}{\partial p^{\prime}}, \quad d \varepsilon_{q}^{p}=d \lambda \frac{\partial f}{\partial q},
$$

where $d \lambda$ is the plastic multiplier that can be determined based on the consistency condition; that is,

$$
d f=\frac{\partial f}{\partial p^{\prime}} d p^{\prime}+\frac{\partial f}{\partial q} d q+\frac{\partial f}{\partial p_{c}} \frac{\partial p_{c}}{\partial \varepsilon_{v}^{p}} d \varepsilon_{v}^{p} .
$$

Substituting (12) into (13) and solving for $d \lambda$, one obtains

$$
d \lambda=-\frac{\left(\partial f / \partial p^{\prime}\right) d p^{\prime}+(\partial f / \partial q) d q}{\left(\partial f / \partial p_{c}\right)\left(\partial p_{c} / \partial \varepsilon_{v}^{p}\right)\left(\partial f / \partial p^{\prime}\right)} .
$$

The yield surface is moving with the evolution of the internal hardening variable $p_{c}$, which is characterized in terms of the double-hardening mechanism [15] in (8). 
The capillary-induced hardening is described by (10), while the plastic volumetric strain hardening is given by

$$
p_{c_{0}}\left(\varepsilon_{v}^{p}\right)=p_{c_{0}}^{*} \exp \left(\frac{v \varepsilon_{v}^{p}}{\lambda-\kappa}\right)
$$

where $p_{c_{0}}^{*}$ is the initial preconsolidation pressure; $\lambda$ is the slope of the normal consolidation line on the $v-\ln p^{\prime}$ plane of the soil under the fully saturated condition.

\subsection{Effect of Deformation on the Soil-Water Characteristic} Curve. Whether or not the hydromechanical behavior of an unsaturated soil can be effectively described at the constitutive level depends largely on the characterization of capillary hysteresis. To characterize the capillary hysteresis, an advanced SWCC model, which can properly address the soil-water characteristics of the soil experiencing arbitrarily wetting/drying cycles, should be properly implemented into a generalized mechanical constitutive framework [13].

Wei and Dewoolkar [18] proposed a thermodynamically consistent model for capillary hysteresis in partially saturated porous media. In this model, the capillary hysteresis phenomenon is linked to intrinsic energy dissipation processes, which can be characterized by the series of internal state variables, $\xi_{i}^{f}$, and the dissipative energy is given by $\zeta_{i}^{f} \delta \xi_{i}^{f}$, as in (5). By virtue of the notion of the bounding surface plasticity, a simplified model of capillary hysteresis is developed. Provided that the main drying-wetting boundary curves have been experimentally determined, the model introduces only one additional parameter to describe all types of scanning curves (primary, secondary, and higher order) under arbitrary hydraulic paths. This model is introduced here to describe the soil-water characteristics.

Experimental results [33] show that in a deformable soil, the sizes and the connectivity of pores may vary with skeletal deformation, which in turn induces change in the soil-water characteristics. For example, the air entry value increases with the decrease of void ratio, and the soil-water characteristic curve may shift upward on the $S_{r}: s_{c}$ plane. To address the effect of deformation on the soil-water characteristic curve, one first notes that, in general, the change in the degree of saturation has two contributions: one is the change in the amount of pore water due to seepage or dissipation, and the other is due to the change in the pore volume, namely,

$$
d S_{r}=d\left(\frac{V_{w}}{V_{v}}\right)=\frac{d V_{w}}{V_{v}}-\left(\frac{V}{V_{v}}\right)\left(\frac{V_{w}}{V_{v}}\right)\left(\frac{d V_{v}}{V}\right) .
$$

As the very meaning of a partial differential, the first item of the right-hand side (r.h.s.) represents the change in the degree of saturation under the constant $-V_{v}$ condition, that is, only due to the change in the amount of pore water, while the second item describes the contribution of the change in volumetric strain. Neglecting the effect of elastic deformation, (16) can be cast into

$$
d S_{r}=\left.d S_{r}\right|_{d \varepsilon_{v}=0}+\frac{S_{r}}{n} d \varepsilon_{v}^{p} .
$$

According to Wei and Dewoolkar [18], the first term of the r.h.s. can be described by

$$
\left.d S_{r}\right|_{d \varepsilon_{v}=0}=\frac{-d s_{c}}{K_{p}\left(s_{c}, S_{r}, \widehat{n}\right)},
$$

where $\widehat{n}$ denotes the hydraulic loading direction, and its value assumes 1 (or -1 ) for drying (or wetting); $K_{p}$ is the negative slope of the current soil-water characteristic curve (either scanning or boundary), which is a function of $s_{c}, S_{r}$, and $\widehat{n}$, given by

$$
K_{p}\left(s_{c}, S_{r}, \widehat{n}\right)=\bar{K}_{p}\left(S_{r}, \widehat{n}\right)+\frac{c\left|s_{c}-\bar{s}_{c}\left(S_{r}, \widehat{n}\right)\right|}{r\left(S_{r}\right)-\left|s_{c}-\bar{s}_{c}\left(S_{r}, \widehat{n}\right)\right|},
$$

where $\bar{K}_{p}\left(S_{r}, \widehat{n}\right)$ is the negative slope of the corresponding main boundary, which is the main drying boundary if $\widehat{n}=1$ or the main wetting boundary if $\widehat{n}=-1 ; c$ is a positive material parameter which is used to describe the scanning behavior; $\bar{s}_{c}\left(S_{r}, \widehat{n}\right)$ is the matric suction value on the corresponding main boundary curve; that is, $\bar{s}_{c}\left(S_{r}, 1\right)=$ $\kappa_{\mathrm{DR}}\left(S_{r}\right)$ for drying and $\bar{s}_{c}\left(S_{r},-1\right)=\kappa_{\mathrm{WT}}\left(S_{r}\right)$ for wetting, where $\kappa_{\mathrm{DR}}\left(S_{r}\right)$ and $\kappa_{\mathrm{WT}}\left(S_{r}\right)$ describe the main drying and wetting boundaries, respectively; $r\left(S_{r}\right)$ is the current size of the bounding zone; that is, $r\left(S_{r}\right)=\kappa_{\mathrm{DR}}\left(S_{r}\right)-\kappa_{\mathrm{WT}}\left(S_{r}\right)$.

Although the effect of change in volumetric strain is excluded in calculating $\left.d S_{r}\right|_{d \varepsilon_{v}=0}$ (via (18)), the volumetric deformation (or change of void ratio) may induce change in the SWCC curve, as mentioned above. That is, function $K_{p}$ should depend explicitly upon the void ratio or equivalently, the total plastic volumetric strain $\varepsilon_{v}^{p}$ (the effect of elastic strain is neglected).

To address this issue, we adopt the following SWCC model by Feng and Fredlund [47] to describe the main boundaries:

$$
\kappa_{k}\left(S_{r}\right)=b_{k}\left(\frac{1-S_{r}}{S_{r}-S_{r}^{\text {irr }}}\right)^{1 / d_{k}}, \quad k=\mathrm{DR}, \mathrm{WT},
$$

where $b_{k}$ and $d_{k}$ are the positive material parameters and assume different values for wetting and drying. The $d_{k}$ parameter determines the curvature of the scanning curves, while $b_{k}$ related to the air-entry value. Ignoring the influence of the elastic volumetric strain and shear strain, $b_{k}$ and $d_{k}$ depend on the plastic volumetric strain, $\varepsilon_{v}^{p}$. Experimental results [33] suggest that the skeletal deformation changes the position of the SWCC only and leaves the shape of the curve almost unchanged. Thus, for simplicity, we propose that

$$
b_{k}=b_{k}^{0}+\alpha_{k} \varepsilon_{v}^{p}, \quad d_{k}=d_{k}^{0},
$$

where $b_{k}^{0}, d_{k}^{0}$, and $\alpha_{k}$ are curving-fitting parameters, $k=\mathrm{DR}$, WT.

Due to a lack of experimental data, it is assumed for simplicity that parameter $c$ is constant, independent of the skeletal deformation. Now, for deforming soils, (19) can be replaced by

$$
\begin{aligned}
& K_{p}\left(\varepsilon_{v}^{p}, s_{c}, S_{r}, \widehat{n}\right) \\
& \quad=\bar{K}_{p}\left(\varepsilon_{v}^{p}, S_{r}, \widehat{n}\right)+\frac{c\left|s_{c}-\bar{s}_{c}\left(\varepsilon_{v}^{p}, S_{r}, \widehat{n}\right)\right|}{r\left(\varepsilon_{v}^{p}, S_{r}\right)-\left|s_{c}-\bar{s}_{c}\left(\varepsilon_{v}^{p}, S_{r}, \widehat{n}\right)\right|} .
\end{aligned}
$$



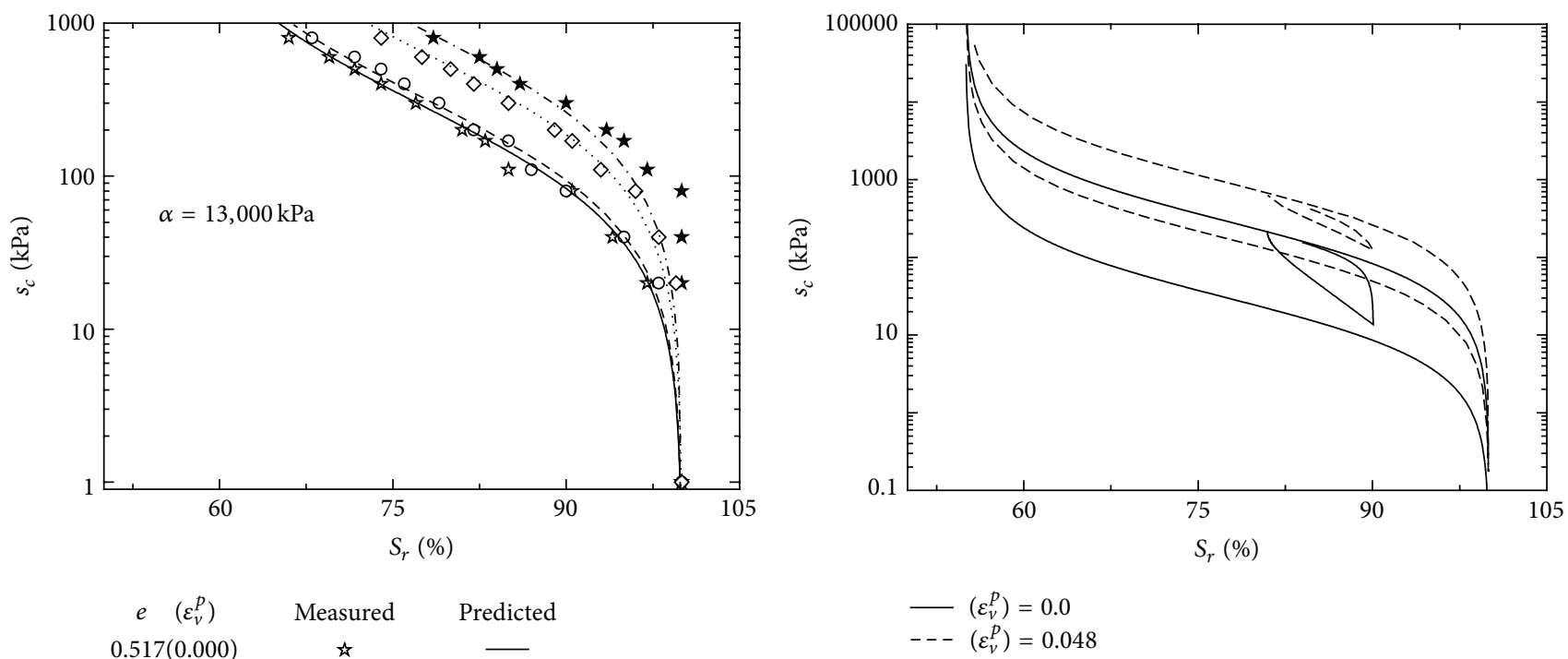

$\begin{array}{ccc}e\left(\varepsilon_{v}^{p}\right) & \text { Measured } & \text { Predicted } \\ 0.517(0.000) & \star & - \\ 0.514(0.002) & \circ & --- \\ 0.474(0.028) & \diamond & \ldots \ldots \\ 0.444(0.048) & \star & .-\cdot\end{array}$

(a)

(b)

FIGURE 4: Effect of plastic volumetric strain on soil-water characteristic curve (data after Vanapalli et al. (1999) [33]).

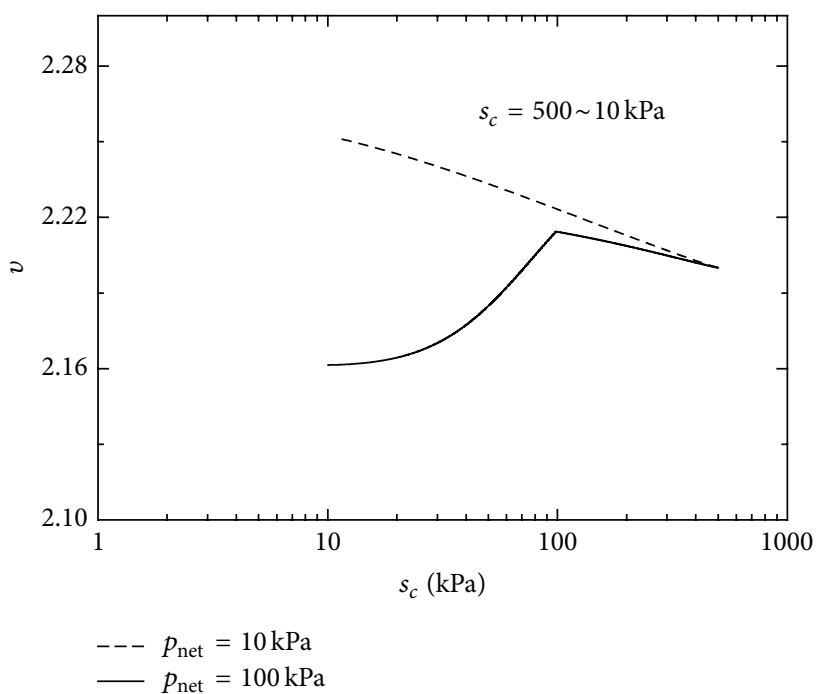

(a)

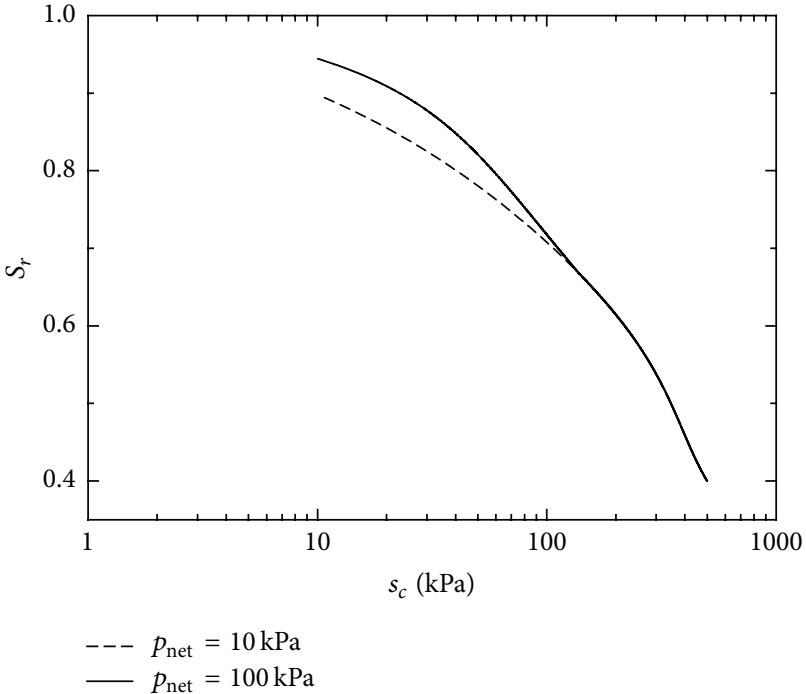

(b)

FIGURE 5: Model prediction for wetting tests at different net stresses: (a) relation between mean net stress and specific volume; (b) soil-water characteristic curve. It is assumed here that $b_{\mathrm{DR}}^{0}=290 \mathrm{kPa}, b_{\mathrm{WT}}^{0}=30 \mathrm{kPa}, S_{r}^{\mathrm{irr}}=0.3, d_{\mathrm{DR}}^{0}=d_{\mathrm{WT}}^{0}=1.0, \alpha_{\mathrm{DR}}=3500 \mathrm{kPa}, \alpha_{\mathrm{WT}}=1500 \mathrm{kPa}$, $r=6.5, m=0.012$, and $\varepsilon_{v, \max }^{p}=0.25$.

As an example, Figure 4(a) illustrates the effect of the plastic volumetric strain on the soil-water characteristic curve. The datum points are inferred from the experimental results in [33]. It can be seen that, while the theoretical simulations agree reasonably well with the experimental results, the model is capable of capturing the main features of the SWCC of deformable soils. The effect of plastic volumetric deformation on capillary hysteresis is schematically shown in Figure 4(b).
2.7. Evaluation of Constitutive Parameters. The proposed model avoids using the LC yield curve as in the traditional framework and introduces the matric suction and degree of saturation into the hardening function as independent variables. The constitutive parameters can be divided into the following three groups.

(1) Group 1: conventional constitutive parameters $-\lambda, \kappa$, $M$, and $G$. 


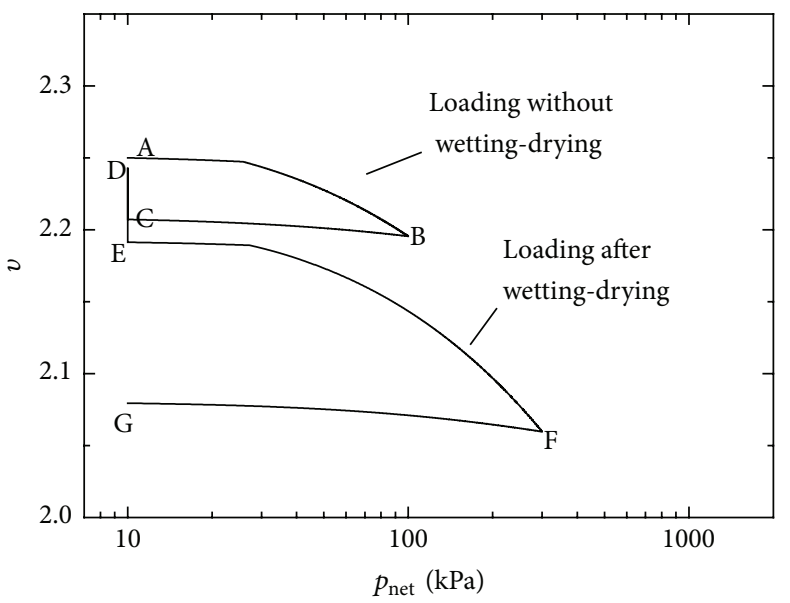

(a)

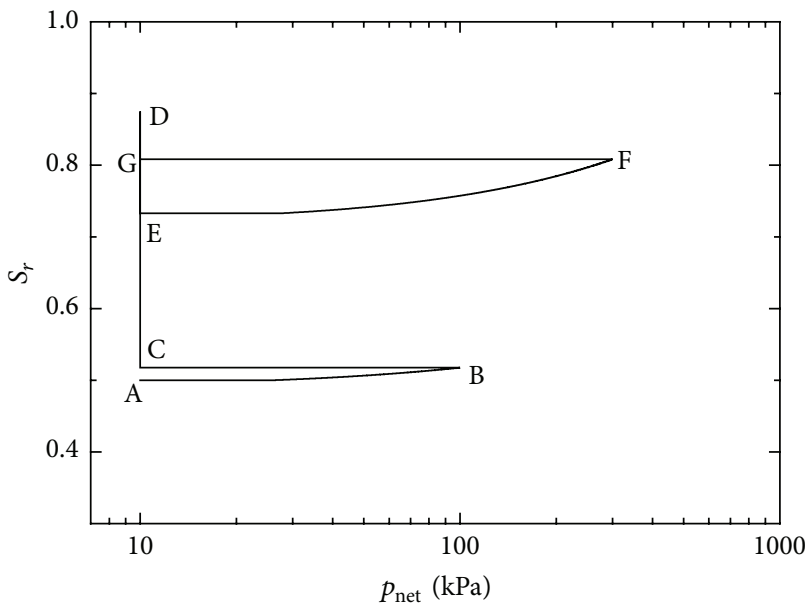

(c)

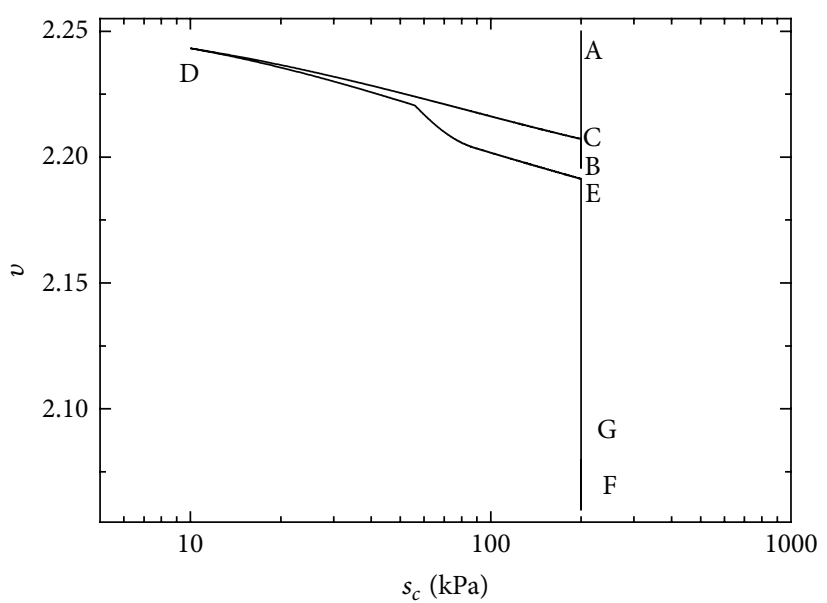

(b)

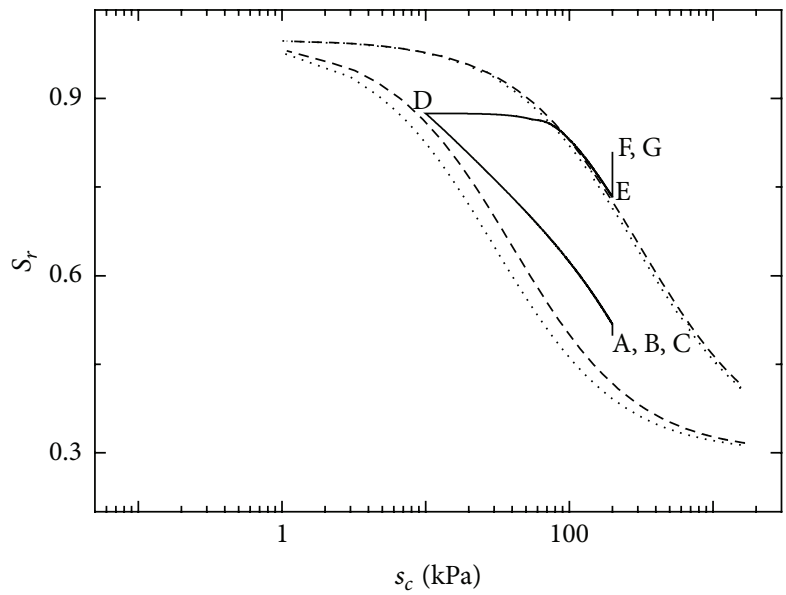

...... Initial boundaries
--- Boundaries at point $\mathrm{C}$
- Scanning curves from $\mathrm{C}$ to $\mathrm{E}$

(d)

FIGURE 6: Influence of wetting-drying cycle on isotropic compression. It is assumed here that $b_{\mathrm{DR}}^{0}=290 \mathrm{kPa}, b_{\mathrm{WT}}^{0}=30 \mathrm{kPa}, d_{\mathrm{DR}}^{0}=d_{\mathrm{WT}}^{0}=1.0$, $S_{r}^{\text {irr }}=0.3, \alpha_{\mathrm{DR}}=1500 \mathrm{kPa}, \alpha_{\mathrm{WT}}=750 \mathrm{kPa}, r=7.5, m=0.0115$, and $\varepsilon_{v, \text { max }}^{p}=0.25$.

(2) Group 2: soil-water characteristic parameters $-b_{\mathrm{DR}}^{0}$, $b_{\mathrm{WT}}^{0}, d_{\mathrm{DR}}^{0}, d_{\mathrm{WT}}^{0}, S_{r}^{\mathrm{irr}}$, and $c$.

(3) Group 3: coupling parameters $-\alpha_{\mathrm{DR}}, \alpha_{\mathrm{WT}}, r, m$, and $\varepsilon_{v, \text { max }}^{p}$.

The parameters in Group 1 can be determined in the same way as those for the modified Cam-Clay model (e.g., [40]). Particularly, $\lambda$ and $\kappa$ are determined from the results of isotropic compression tests, while $M$ and $G$ (or Poisson's ratio $v$ ) are obtained by performing the triaxial compression tests on saturated soil.

The parameters in Group 2 can be determined, via a curve-fitting procedure, by measuring the soil-water characteristic curve for the soil experiencing wetting/drying cycles. Parameters $b_{\mathrm{DR}}^{0}, b_{\mathrm{WT}}^{0}, d_{\mathrm{DR}}^{0}, d_{\mathrm{WT}}^{0}$, and $S_{r}^{\mathrm{irr}}$ are determined based on the measurement of the two boundary curves [47]. With knowledge of the two boundary curves, $c$ is determined by fitting the theoretical simulation of a primary scanning curve with the measured one [18].

Among the parameters in Group 3, $r, m$, and $\varepsilon_{v, \text { max }}^{p}$ can be determined by measuring the variation of preconsolidation pressure with the matric suction or degree of saturation during a drying process; parameters $\alpha_{\mathrm{DR}}$ and $\alpha_{\mathrm{WT}}$, which represent the influence of plastic deformation on the soilwater characteristic curve, can be obtained by comparing the soil-water characteristic curves under deformed and undeformed conditions.

\section{Model Performance}

3.1. Wetting under Different Net Pressures. Figure 5 shows the simulated results of the wetting tests on an unsaturated clayey soil under constant net pressures of $10 \mathrm{kPa}$ and $100 \mathrm{kPa}(q=$ $0 \mathrm{kPa}$ ), respectively. The soil sample was wetted from $s_{c}=$ $500 \mathrm{kPa}$ to $s_{c}=10 \mathrm{kPa}$, while the net pressure remained 


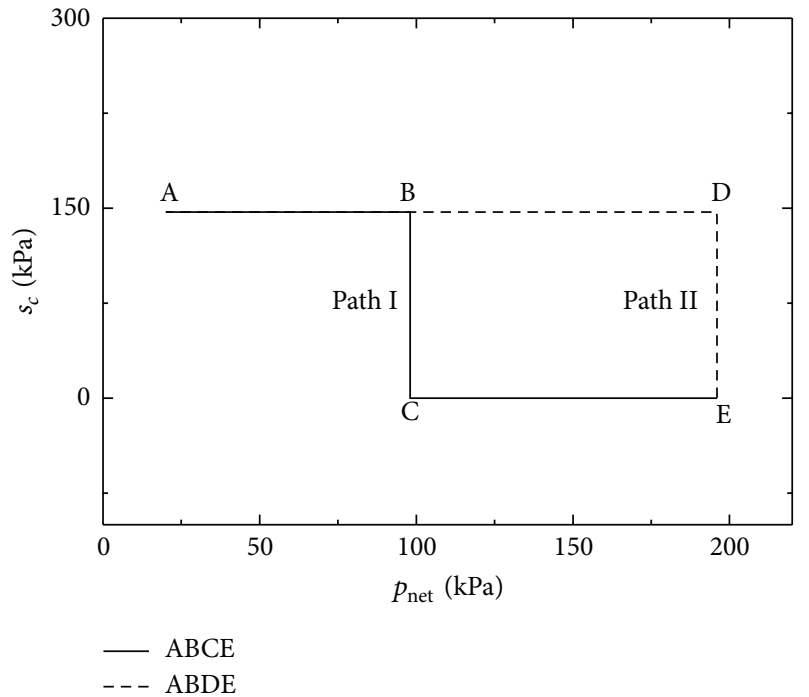

(a)

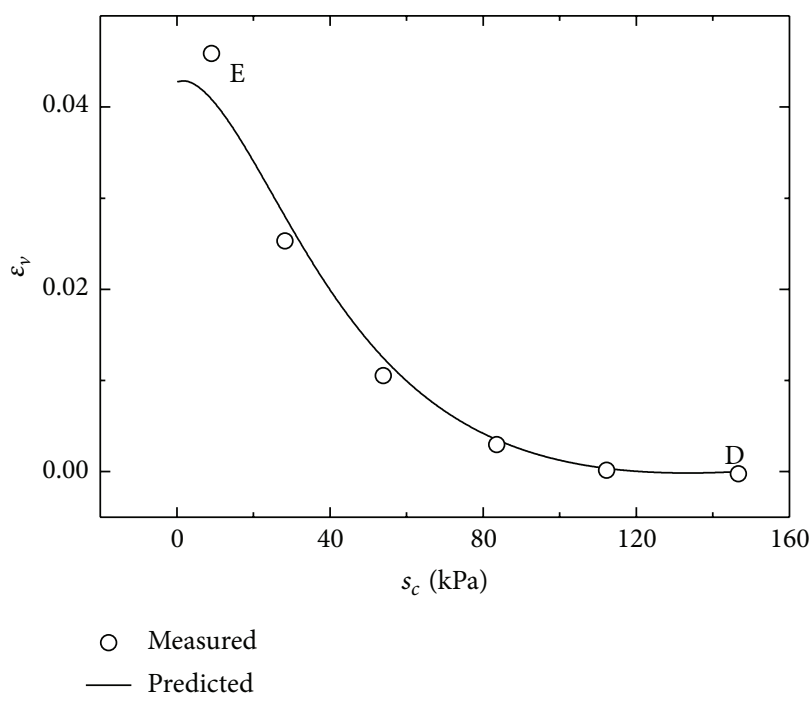

(c)

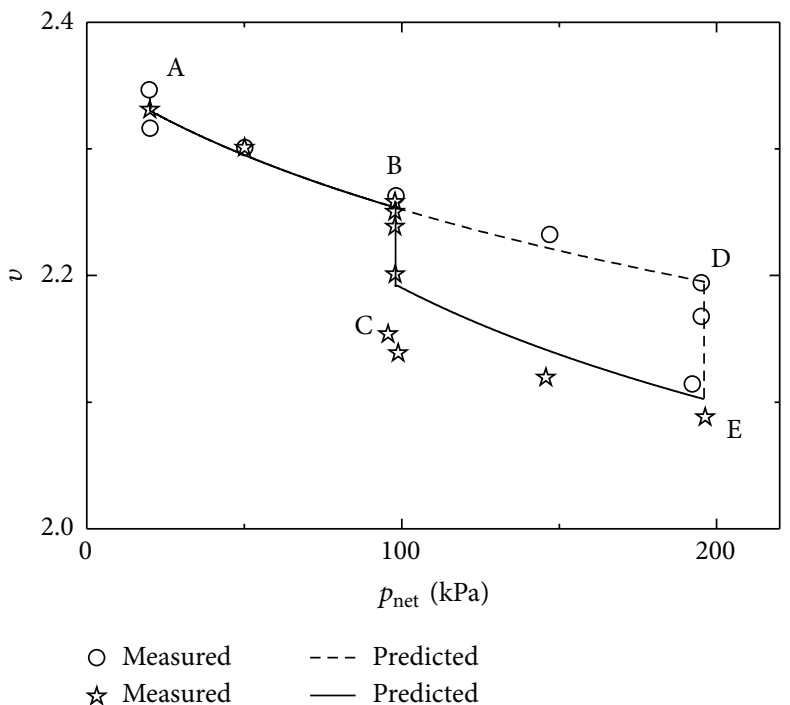

(b)

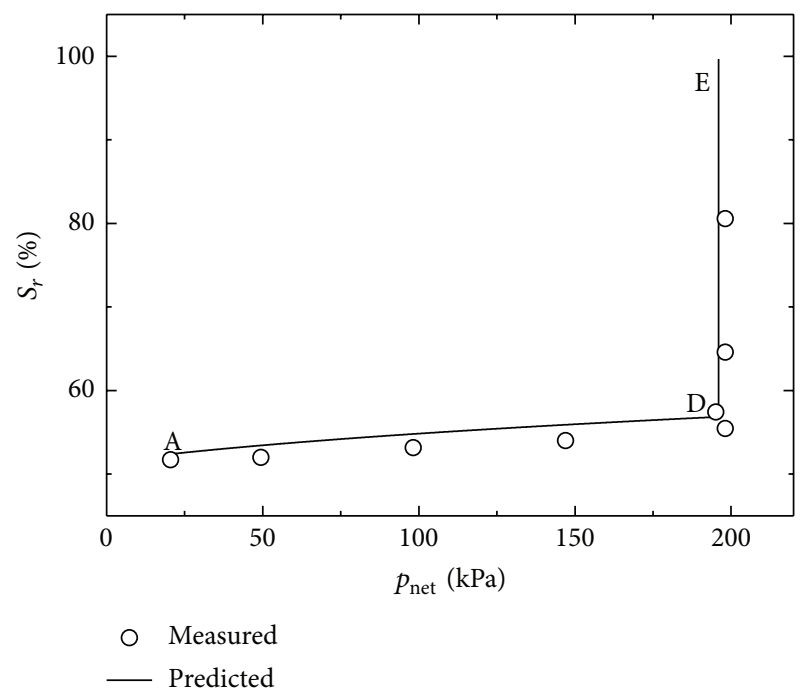

(d)

FIGURE 7: Simulated and measured results of wetting-collapse experiments on Pearl clay: (a) stress paths adopted; (b) relation between $p_{\text {net }}$ and $v$; (c) variation of total volumetric strain with matric suction during the wetting process $\mathrm{D}$-E; (d) variation of the degree of saturation with net pressure for Path A-B-D-E. (data after Sun et al. (2007) [34]).

constant. It can be seen from Figure 5(a) that, under small net pressure $(10 \mathrm{kPa})$, the soil exhibits only elastic swelling during the wetting process, whereas, at high net pressure $(100 \mathrm{kPa})$, after slightly swelling in the early beginning, significant plastic compression can occur. Figure 5(b) shows that plastic volumetric deformation can significantly influence the soilwater characteristics. These simulated results are consistent with experimental observations [34].

During a wetting process, both mean skeleton stress $p^{\prime}$ and preconsolidation pressure $p_{c}$ will decrease, triggering two competitive mechanisms. While the soil swells elastically with $p^{\prime}$ decreasing due to wetting, the yield pressure also becomes smaller and smaller. Under a small net pressure (say $10 \mathrm{kPa}$ in the present case), $p^{\prime}$ is always smaller than $p_{c}$ during the whole wetting process, so that only elastic swelling deformation can occur. At high net pressure (say $100 \mathrm{kPa}$ in the present case), however, $p^{\prime}$ may reach $p_{c}$ during the wetting process, resulting in plastic deformation.

3.2. Effect of Hydraulic History on Compression. The simulated results of an isotropic loading-unloading compression test on a silty clay are presented in Figure 6. At a constant matric suction of $200 \mathrm{kPa}$, the soil was first loaded from A $\left(p_{\text {net }}=10 \mathrm{kPa}\right)$ to B $\left(p_{\text {net }}=100 \mathrm{kPa}\right)$ and then unloaded to $\mathrm{C}\left(p_{\text {net }}=10 \mathrm{kPa}\right)$; after a wetting-drying cycle C-D-E $\left(s_{c}=\right.$ $200 \rightarrow 10 \rightarrow 200 \mathrm{kPa})$ at $p_{\text {net }}=10 \mathrm{kPa}$, the soil was reloaded to $\mathrm{F}$ ( $p_{\text {net }}=300 \mathrm{kPa}$ ) and finally unloaded to $\mathrm{G}$ $\left(p_{\text {net }}=10 \mathrm{kPa}\right)$, at a constant matric suction of $200 \mathrm{kPa}$.

Figure 6(a) reveals that the yielding pressure during isotropic compression at a given value of suction is reduced 


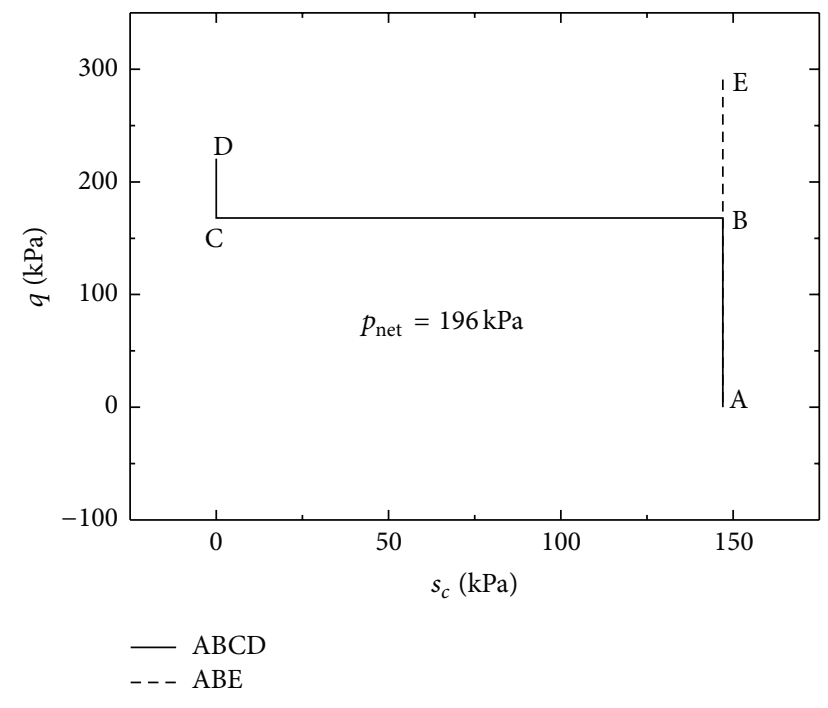

FIgURE 8: Stress paths used in the triaxial tests.

by a preceding wetting-drying cycle, which is consistent with the experimental observation [48]. This phenomenon can be largely attributed to the capillary hysteresis. As shown in Figure 6(c), there has been a significant increase in the degree of saturation during the wetting-drying cycle C-D-E, resulting in a decrease in the preconsolidation pressure. Clearly, the proposed model can correctly predict the dependence of the soil response on its hydraulic history during isotropic compression under constant suction.

Figure 6(b) shows that significant irreversible compression has occurred during the wetting-drying cycle. In the wetting phase from $\mathrm{C}$ to $\mathrm{D}$, the stress state resides in the elastic domain (i.e., $p^{\prime}<p_{c}$ ), though both mean skeleton stress $p^{\prime}$ and preconsolidation pressure $p_{c}$ decrease simultaneously. In the drying phase from $\mathrm{D}$ to $\mathrm{E}$, although both $p^{\prime}$ and $p_{c}$ increase simultaneously, $p^{\prime}$ increases faster than $p_{c}$, so that the stress state of the soil touches the yield locus when the matric suction increases up to a certain value, resulting in plastic deformation. Remarkably, if the effect of capillary hysteresis is neglected, the model would have predicted that the soil is elastically compressed to Point $\mathrm{C}$ again; that is, $\mathrm{C}$ coincides with $\mathrm{E}$.

Figure 6(d) illustrates the effect of deformation on the soil-water characteristics. After the first loading-unloading cycle A-B-C, the SWCC boundaries (both wetting and drying) shift rightward on the $S_{r}: s_{c}$ plane, due to the plastic compression of the soil matrix. In the wetting process from C to D, only elastic deformation occurs, and the SWCC boundaries remain unchanged. During the drying process from D to E, plastic deformation occurs, and the SWCC boundaries move rightward with the deformation until the drying boundary crosses Point $\mathrm{E}$. In the reloading process from $\mathrm{E}$ to $\mathrm{F}$, plastic deformation further drives the SWCC boundaries rightward, and the SWCC boundaries remain fixed during the unloading process from F to G. Although
TABLE 1: Index properties of Pearl clay [34].

\begin{tabular}{lc}
\hline Property & Definition \\
\hline Grain-size distribution & Silt $=50 \%$, clay $=50 \%$ \\
Atterberg limits & $\mathrm{LL}=49 \%, \mathrm{PI}=27 \%$ \\
Specific gravity & $G_{s}=2.71$ \\
\hline
\end{tabular}

further experimental justification is needed, limited experimental data suggest that the above model prediction is reasonable $[34,35]$.

3.3. Wetting-Induced Compression (Wetting-Collapse Test). Sun et al. [34] have conducted isotropic compression and wetting-collapse experiments on Pearl clay (a silty clay), the physical properties of which are given in Table 1 . In these experiments, two stress paths (i.e., A-B-C-E and A-B-D-E) were adopted (Figure 7(a)). Some of typical experimental results are illustrated in Figures $7(\mathrm{~b})-7(\mathrm{~d})$. The initial water content and void ratio of the tested soil samples are about $26 \%$ and 1.34, respectively. Due to lacking of experimental data, the hydraulic and mechanical constitutive parameters are determined based on the curve-fitting process and given in Tables 2 and 3, respectively.

Along with Path A-B-C-E, the soil was first compressed under the isotropic condition from Point $\mathrm{A}$ ( $p_{\text {net }}=20 \mathrm{kPa}$ ) to Point $\mathrm{B}\left(p_{\text {net }}=98 \mathrm{kPa}\right)$ at a constant matric suction of $147 \mathrm{kPa}$, then wetted from Point $B$ to the fully saturated condition (Point C) under a constant net pressure of $98 \mathrm{kPa}$, and finally compressed to Point $\mathrm{E}$ ( $p_{\text {net }}=196 \mathrm{kPa}$ ) under fully saturated conditions. With Path A-B-D-E, the soil was compressed under the isotropic condition from Point $\mathrm{A}\left(p_{\text {net }}=20 \mathrm{kPa}\right)$ to Point $\mathrm{D}\left(p_{\text {net }}=196 \mathrm{kPa}\right)$ at a constant matric suction of $147 \mathrm{kPa}$ and then wetted to the fully saturated condition under a constant net pressure of $196 \mathrm{kPa}$.

The simulations for the variation of specific volume with net pressure are given in Figure 7(b), showing that overall the simulations agree well with the experimental data. It is remarkable, however, that during the loading process C-E, the model overestimates the specific volume. Such a discrepancy can be attributed to the following two reasons: (1) the plastic deformation is underestimated by the model during the wetting process $\mathrm{B}-\mathrm{C}$, and (2), when the soil approached to full saturation at Point $C$ (from Point B), small amount of air was trapped in the pores, rendering the soil to be more compressible than expected in the early beginning of the subsequent compression process.

Figure 7(c) illustrates the variation of volumetric strain during the wetting process from D to E. Although slight swelling deformation is predicted in the early beginning of the wetting process, the model simulation agrees generally well with the measurements. Figure 7(d) depicts the variation of saturation with net stress for Path A-B-D-E. The simulated result deviates from the measurement at the final stage of the wetting process $\mathrm{D}$-E; that is, the calculated degree of saturation at Point $\mathrm{E}$ is $100 \%$, which is larger than the measured value. Apparently, this discrepancy can be attributed to the air entrapment, which has not been considered in the proposed 


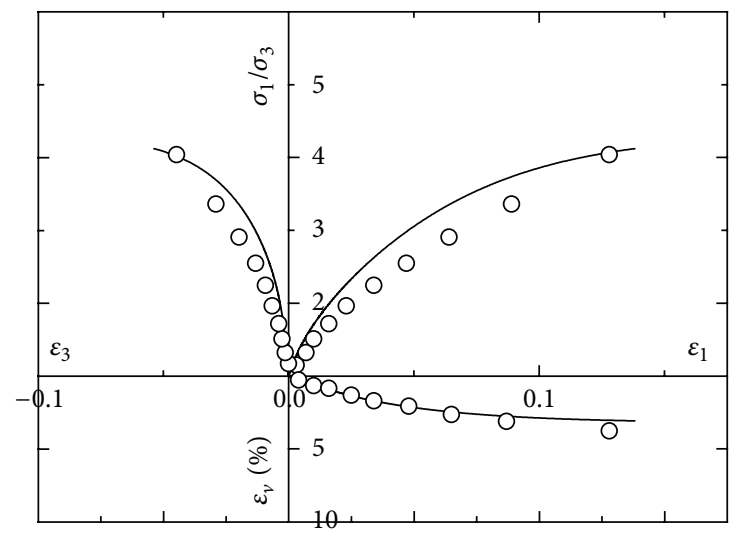

O Measured — Predicted

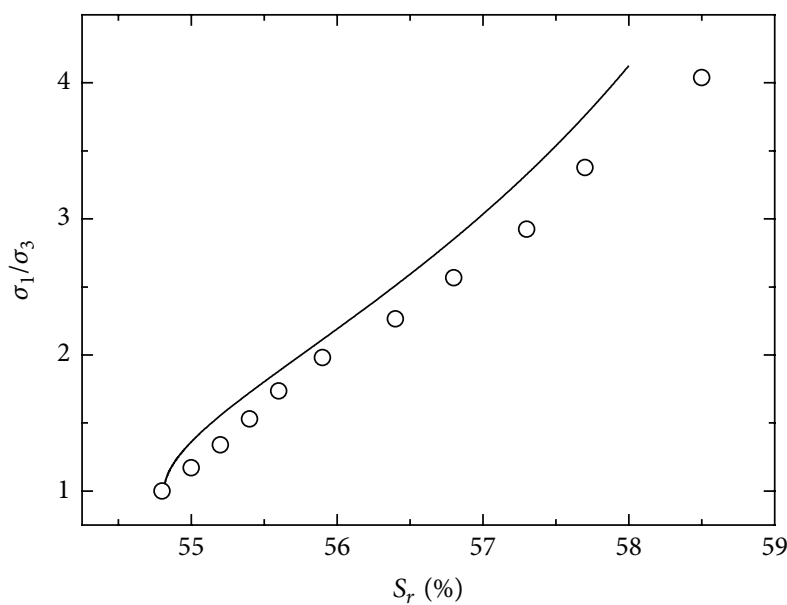

O Measured

— Predicted

(a)

(b)

FIGURE 9: Simulated and measured results of triaxial tests with stress Path A-B-E (data after Sun et al. (2007) [2]).

TABle 2: Mechanical parameters of Pearl clay.

\begin{tabular}{lcccccc}
\hline$\lambda$ & $\kappa$ & $G(\mathrm{kPa})$ & $r$ & $m$ & $p_{c_{0}}^{*}$ & $\varepsilon_{v, \max }^{p}$ \\
\hline 0.12 & 0.03 & 5000 & 4.5 & 0.035 & 20.15 & 0.25 \\
\hline
\end{tabular}

model. In spite of this shortcoming, the model can very well predict the trend of variation for the degree of saturation.

3.4. Suction-Controlled Triaxial Tests. Sun et al. [2] have performed a series of suction-controlled triaxial compression tests on Pearl clay. The stress paths adopted in these experiments are illustrated in Figure 8. The experimental results are given in Figures 9 and 10 for Path A-B-E and Path AB-C-D, respectively. Along with stress path A-B-E, the soil sample was sheared from an initial isotropic state to failure by increasing $q$ under $p_{\text {net }}=196 \mathrm{kPa}$ and $s_{c}=147 \mathrm{kPa}$. With stress Path A-B-C-D, the sample was first sheared, under $p_{\text {net }}=196 \mathrm{kPa}$ and $s_{c}=147 \mathrm{kPa}$, from Point A to Point B until principal stress ratio $\sigma_{1} / \sigma_{3}$ reached about 2.2; then the sample was wetted from Point $\mathrm{B}$ to the fully saturated condition (Point C) under constant- $p_{\text {net }}$ and constant- $q$ conditions; finally, the sample was sheared to failure from Point $C$ by increasing $q$.

The material properties adopted in the simulations are the same as those given in Tables 1-3. Figures 9(a) and 9(b) depict the relations among $\sigma_{1} / \sigma_{3}, \varepsilon_{1}, \varepsilon_{3}$, and $\varepsilon_{v}$ and the relation between $\sigma_{1} / \sigma_{3}$ and the degree of saturation, respectively. For stress Path A-B-E, in the early of shearing, the model predicts that the specimen remains in the elastic domain, as illustrated by the initial vertical line segment in Figure 9(b) (note that the effect of elastic volumetric strain on the degree of saturation has been neglected). From Figure 9(a), it is clear that although the model slightly underestimates the axial strain and the lateral strain, overall it yields good results.

Figure 10(a) shows that the lateral strain is overestimated in the later stage of the shearing process. In spite of this discrepancy, the model simulations agree well with the experimental data. From Figure 10(b), it can be seen that, during the wetting process (from $\mathrm{B}$ to $\mathrm{C}$ ), the model predicts the full saturation at Point $\mathrm{C}$, which is inconsistent with the measurement. This discrepancy is due to the effect of air entrapment in the experiment, which is also responsible for the discrepancy between the predicted and measured strains (see Figure 10(a)). To take into account the air entrapment effect, slight improvement of the proposed model is required, which goes beyond the scope of this paper. Remarkably, the degree of saturation increases during the shearing process, and this feature has been well captured by the proposed model, as illustrated in Figures 9(b) and 10(b).

3.5. Wetting-Drying Cycle under Constant Net Pressure. Figure 11 gives the simulated and experimental results of a wetting-drying experiment on the Pearl clay under constant net pressure. The experimental data are obtained from [35]. The tested sample has an initial void ratio $e_{0}$ of 1.08 , and it is much denser than those samples mentioned in Sections 3.3 and 3.4 (for latter cases, $e_{0} \approx 1.34$ ). During the wettingdrying cycles, the matric suction first decreased from $196 \mathrm{kPa}$ to $2 \mathrm{kPa}$ (from $\mathrm{A}^{\prime}$ to $\mathrm{B}^{\prime}$ ), then increased from about 2 to $490 \mathrm{kPa}$ (from $\mathrm{B}^{\prime}$ to $\mathrm{C}^{\prime}$ ), and finally decreased from 490 to about $2 \mathrm{kPa}$ (from $\mathrm{C}^{\prime}$ to $\mathrm{D}^{\prime}$ ), while the net pressure remained $20 \mathrm{kPa}$.

The material properties used in the simulation are given in Tables 1-3. It is noted, however, that several parameters (namely, $b_{\mathrm{DR}}, b_{\mathrm{WT}}, \varepsilon_{v, \max }^{p}$, and $p_{\mathcal{c}_{0}}^{*}$ ) need to be slightly modified in order to account for the effect of the initial density of the sample. The new values of these parameters are $b_{\mathrm{DR}}=$ $220 \mathrm{kPa}, b_{\mathrm{WT}}=60 \mathrm{kPa}, \varepsilon_{v, \text { max }}^{p}=0.15$, and $p_{c_{0}}^{*}=37.05 \mathrm{kPa}$. 


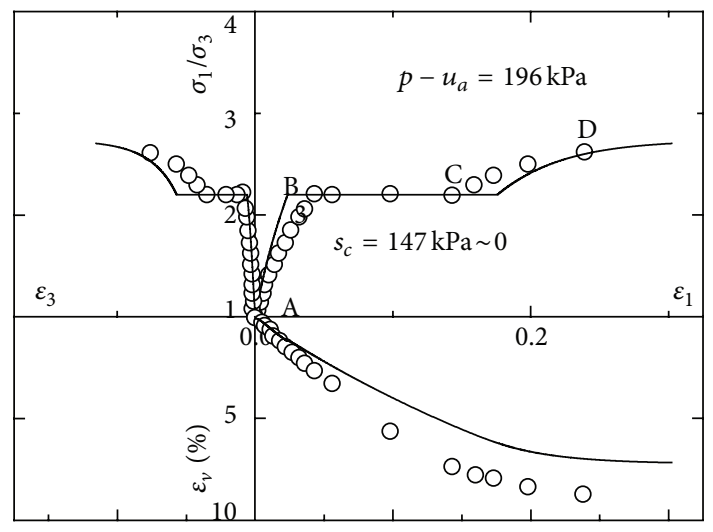

(a)

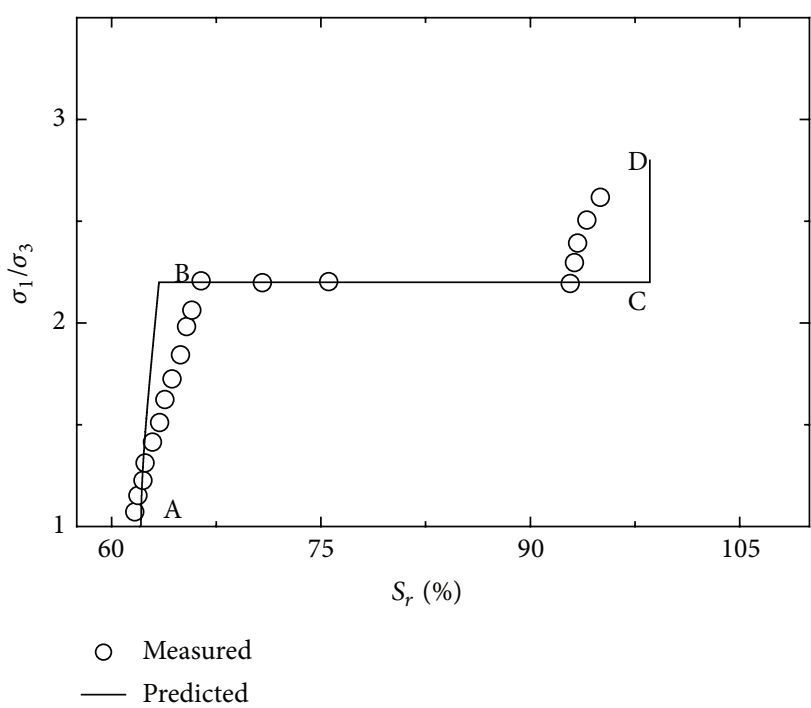

(b)

FIgURE 10: Simulated and measured results of triaxial tests with stress Path A-B-C-D (data after Sun et al. (2007) [2]).

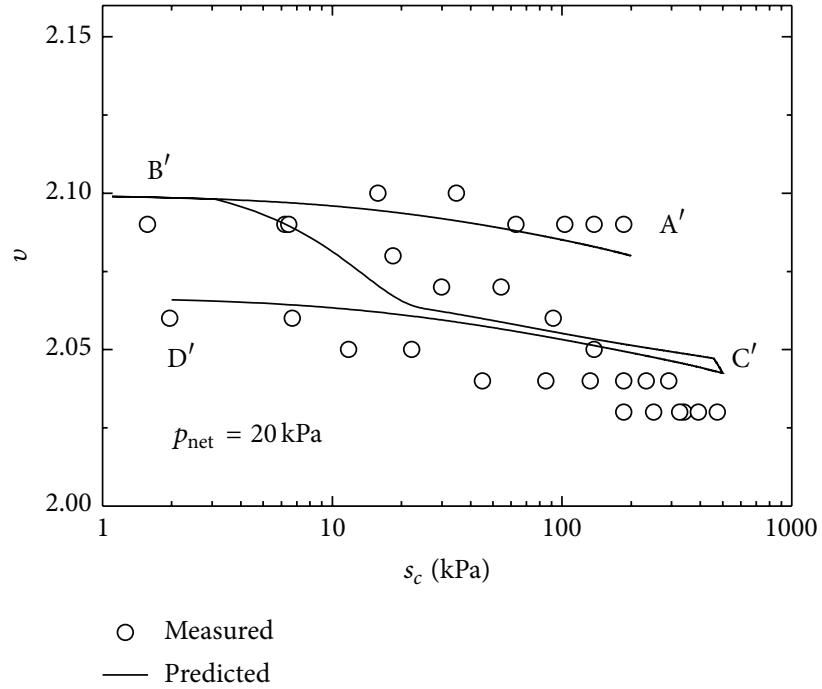

(a)

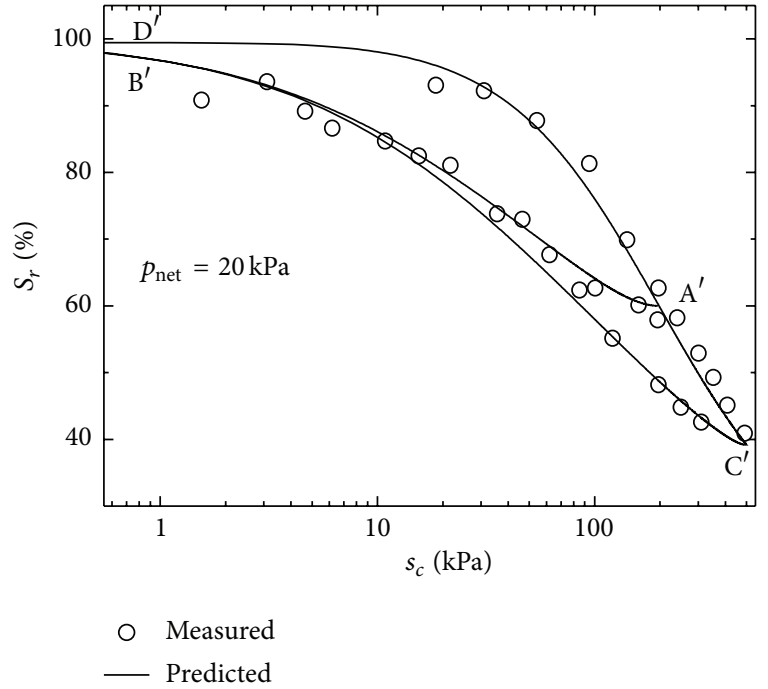

(b)

FIGURE 11: Response of Pearl clay under wetting-drying cycles: (a) relation between matric suction and specific volume; (b) soil-water characteristic curve (data after Sun et al. (2006) [35]).

Figure 11(a) depicts the variation of the specific volume with matric suction. It can be seen that the model simulation agrees reasonably well with the experimental data. Particularly, the model correctly predicts that plastic deformation occurs during the drying process from $B^{\prime}$ to $C^{\prime}$. Figure 11(b) illustrates that the model can very well describe the soilwater characteristics of the unsaturated soil under deforming conditions.

\section{Conclusions}

The two major dissipative mechanisms in unsaturated soils, that is, capillary hysteresis and plastic deformation, are discussed in this paper. The capillary hysteresis is viewed as a phenomenon associated with the internal structural rearrangements in unsaturated soils, which can be characterized by using a set of internal state variables. As such, both capillary hysteresis and plastic deformation are systematically and consistently addressed in a unified theoretical framework. Within this context and based on the modified Cam-Clay model, a constitutive model of unsaturated soils is developed, which can effectively describe the coupling of capillary hysteresis and skeletal deformation.

In the new model, a hardening function is introduced in which both the matric suction and the degree of saturation are explicitly included as hardening variables, so that 
TABLE 3: Hydraulic parameters of Pearl clay.

\begin{tabular}{lccccccc}
\hline$b_{\mathrm{DR}}^{0}(\mathrm{kPa})$ & $b_{\mathrm{WT}}^{0}(\mathrm{kPa})$ & $d_{\mathrm{DR}}^{0}$ & $d_{\mathrm{WT}}^{0}$ & $S_{r}^{\text {irr }}$ & $c(\mathrm{kPa})$ & $\alpha_{\mathrm{DR}}(\mathrm{kPa})$ & $\alpha_{\mathrm{WT}}(\mathrm{kPa})$ \\
\hline 181.15 & 43.35 & 1.2 & 0.8 & 0.2 & 1000 & 350 & 150 \\
\hline
\end{tabular}

the effect of hydraulic history on the mechanical response can be properly addressed. The soil-water characteristic curve is introduced not only to describe the capillary hysteresis in the unsaturated soils experiencing arbitrary wetting/drying cycles, but also to characterize the effect of hydraulic history on the skeletal deformation. The new model is used to simulate the mechanical response of unsaturated soil under various loading conditions, showing that it is capable of capturing the main features of the unsaturated soil behavior.

The new model has a hierarchical structure, and it can describe the stress-strain relation and the soil-water characteristics in a coupled or uncoupled manner. When the coupling effect of skeletal deformation and capillary hysteresis is neglected, the new model ends up with two major constitutive relationships for unsaturated soils, namely, the stress-strain relationship and the soil-water characteristic curve. Without skeletal deformation, the model describes the soil-water characteristics only. When the soil becomes fully saturated, the model transits smoothly into the modified Cam-Clay model of saturated soils.

\section{Acknowledgments}

The research was supported by the Natural Science Foundation of China (Grant no. 11072255) and the Natural Science Foundation of Guangxi (Grant no. 2011GXNSFE018004).

\section{References}

[1] S. J. Wheeler, "Inclusion of specific water volume within an elasto-plastic model for unsaturated soil," Canadian Geotechnical Journal, vol. 33, no. 1, pp. 42-57, 1996.

[2] D. Sun, D. Sheng, and S. W. Sloan, "Elastoplastic modelling of hydraulic and stress-strain behaviour of unsaturated soils," Mechanics of Materials, vol. 39, no. 3, pp. 212-221, 2007.

[3] C. W. W. Ng and Y. W. Pang, "Influence of stress state on soilwater characteristics and slope stability," Journal of Geotechnical and Geoenvironmental Engineering, vol. 126, no. 2, pp. 157-166, 2000.

[4] E. E. Alonso, A. Gens, and A. Josa, "A constitutive model for partially saturated soils," Géotechnique, vol. 40, no. 3, pp. 405430, 1990.

[5] S. J. Wheeler and V. Sivakumar, "An elasto-plastic critical state framework for unsaturated soil," Géotechnique, vol. 45, no. 1, pp. 35-53, 1995.

[6] M. Nuth, L. Laloui, and B. A. Schrefler, "Analysis of compaction phenomena due to water injection in reservoirs with a threephase geomechanical model," Journal of Petroleum Science and Engineering, vol. 73, no. 1-2, pp. 33-40, 2010.

[7] D. A. Sun and X. Li, "An elastoplastic hydro-mechanical model for unsaturated soils," in Proceedings of the 7th International Conference on Computational Science (ICCS '07), pp. 1138-1145, Springer, Beijing, China, 2007.
[8] D. Sheng, A. Gens, D. G. Fredlund, and S. W. Sloan, "Unsaturated soils: from constitutive modelling to numerical algorithms," Computers and Geotechnics, vol. 35, no. 6, pp. 810-824, 2008.

[9] F. D’Onza, D. Gallipoli, S. Wheeler et al., "Benchmark of constitutive models for unsaturated soils," Géotechnique, vol. 61, no. 4, pp. 283-302, 2011.

[10] S. J. Wheeler, R. S. Sharma, and M. S. R. Buisson, "Coupling of hydraulic hysteresis and stress-strain behaviour in unsaturated soils," Géotechnique, vol. 53, no. 1, pp. 41-54, 2003.

[11] G. Bolzon, B. A. Schrefler, and O. C. Zienkiewicz, "Elastoplastic soil constitutive laws generalized to partially saturated states," Géotechnique, vol. 46, no. 2, pp. 279-289, 1996.

[12] Y. J. Cui and P. Delage, "Yielding and plastic behaviour of an unsaturated compacted silt," Géotechnique, vol. 46, no. 2, pp. 291-311, 1996.

[13] M. Nuth, Constitutive modelling of unsaturated soils with hydrogeomechanical couplings [Ph.D. thesis], Ecole Polytechnique Fédérale de Lausanne (EPFL), Lausanne, Switzerland, 2009.

[14] N. Khalili, F. Geiser, and G. E. Blight, "Effective stress in unsaturated soils: review with new evidence," International Journal of Geomechanics, vol. 4, no. 2, pp. 115-126, 2004.

[15] R. Tamagnini, "An extended Cam-clay model for unsaturated soils with hydraulic hysteresis," Géotechnique, vol. 54, no. 3, pp. 223-228, 2004.

[16] C. Jommi, "Remarks on the constitutive modelling of unsaturated soils," in Experimental Evidence and Theoretical Approaches in Unsaturated Soils. Proceedings of the International Workshop on Unsaturated Soils, A. Tarantino and C. Mancuso, Eds., pp. 139-153, Balkema, Rotterdam, The Netherlands, 2000.

[17] X. S. Li, "Thermodynamics-based constitutive framework for unsaturated soils. 2: a basic triaxial model," Géotechnique, vol. 57, no. 5, pp. 423-435, 2007.

[18] C. Wei and M. M. Dewoolkar, "Formulation of capillary hysteresis with internal state variables," Water Resources Research, vol. 42, no. 7, Article ID W07405, 2006.

[19] X. S. Li, "Modelling of hysteresis response for arbitrary wetting/drying paths," Computers and Geotechnics, vol. 32, no. 2, pp. 133-137, 2005.

[20] Y. Mualem, “A conceptual model of hysteresis," Water Resources Research, vol. 10, no. 3, pp. 514-520, 1974.

[21] J. Y. Parlange, "Capillary hysteresis and the relationship between drying and wetting curves," Water Resources Research, vol. 12, no. 2, pp. 224-228, 1976.

[22] L. Miao, F. Jing, and S. L. Houston, "Soil-water characteristic curve of remolded expansive soils," in Proceedings of the 4th International Conference on Unsaturated Soils, pp. 997-1004, April 2006.

[23] D. Gallipoli, S. J. Wheeler, and M. Karstunen, "Modelling the variation of degree of saturation in a deformable unsaturated soil," Géotechnique, vol. 53, no. 1, pp. 105-112, 2003.

[24] M. T. van Genuchten, "A closed-form equation for predicting the hydraulic conductivity of unsaturated soils," Soil Science Society of America Journal, vol. 44, no. 5, pp. 892-898, 1980. 
[25] X. S. Li, "Thermodynamics-based constitutive framework for unsaturated soils. 1: theory," Géotechnique, vol. 57, no. 5, pp. 411422, 2007.

[26] G. T. Houlsby, “The work input to an unsaturated granular material," Géotechnique, vol. 47, no. 1, pp. 193-196, 1997.

[27] A. W. Bishop, “The principle of effective stress bishop," Teknisk Ukeblad, vol. 106, no. 39, pp. 113-143, 1959.

[28] N. Khalili and S. Zargarbashi, "Influence of hydraulic hysteresis on effective stress in unsaturated soils," Géotechnique, vol. 60, no. 9, pp. 729-734, 2010.

[29] E. E. Alonso, J.-M. Pereira, J. Vaunat, and S. Olivella, "A microstructurally based effective stress for unsaturated soils," Géotechnique, vol. 60, no. 12, pp. 913-925, 2010.

[30] J.-M. Pereira, O. Coussy, E. E. Alonso, J. Vaunat, and S. Olivella, "Is the degree of saturation a good candidate for Bishop's parameter?" in Proceedings of the 5th International Conference on Unsaturated Soils, E. E. Alonso and A. Gens, Eds., pp. 913919, CRC Press, Barcelona, Spain, September 2010.

[31] T. Cadoret, G. Mavko, and B. Zinszner, "Fluid distribution effect on sonic attenuation in partially saturated limestones," Geophysics, vol. 63, no. 1, pp. 154-160, 1998.

[32] C. Wei and K. K. Muraleetharan, "Linear viscoelastic behavior of porous media with non-uniform saturation," International Journal of Engineering Science, vol. 45, no. 2-8, pp. 698-715, 2007.

[33] S. K. Vanapalli, D. G. Fredlund, and D. E. Pufahl, "The influence of soil structure and stress history on the soil-water characteristics of a compacted till," Géotechnique, vol. 49, no. 2, pp. 143-159, 1999.

[34] D. Sun, D. Sheng, and Y. Xu, "Collapse behaviour of unsaturated compacted soil with different initial densities," Canadian Geotechnical Journal, vol. 44, no. 6, pp. 673-686, 2007.

[35] D. A. Sun, D. C. Sheng, H. B. Cui, and S. W. Sloan, "A densitydependent elastoplastic hydro-mechanical model for unsaturated compacted soils," International Journal for Numerical and Analytical Methods in Geomechanics, vol. 31, no. 11, pp. 12571279, 2007.

[36] T. Cadoret, D. Marion, and B. Zinszner, "Influence of frequency and fluid distribution on elastic wave velocities in partially saturated limestones," Journal of Geophysical Research, vol. 100, no. 6, pp. 9789-9803, 1995.

[37] R. Knight and R. Nolen-Hoeksema, "A laboratory study of the dependence of elastic wave velocities on pore scale fluid distribution," Geophysical Research Letters, vol. 17, no. 10, pp. 1529-1532, 1990.

[38] M. Le Ravalec, Y. Guéguen, and T. Chelidze, "Elastic wave velocities in partially saturated rocks: saturation hysteresis," Journal of Geophysical Research B, vol. 101, no. 1, pp. 837-844, 1996.

[39] J. R. Rice, "Inelastic constitutive relations for solids: an internalvariable theory and its application to metal plasticity," Journal of the Mechanics and Physics of Solids, vol. 19, no. 6, pp. 433-455, 1971.

[40] K. H. Roscoe and J. B. Burland, "On the generalized stress-strain behavior of 'wet' clay,' in Engineering Plasticity, pp. 535-609, Cambridge University Press, Cambridge, UK, 1968.

[41] L. Luckner, M. T. van Genuchten, and D. R. Nielsen, "A consistent set of parametric models for the two-phase flow of immiscible fluids in the subsurface," Water Resources Research, vol. 25, no. 10, pp. 2187-2193, 1989.
[42] W. S. Sillers, The mathematical representation of the soil-water characteristic curve [Ph.D. thesis], University of Saskatchewan, Saskatchewan, Canada, 1997.

[43] D. Gallipoli, A. Gens, R. Sharma, and J. Vaunat, "An elastoplastic model for unsaturated soil incorporating the effects of suction and degree of saturation on mechanical behaviour," Géotechnique, vol. 53, no. 1, pp. 123-135, 2003.

[44] R. A. Fisher, "On the capillary forces in an ideal soil; correction of formulae given by W. B. Haines," Journal of Agricultural Science, vol. 16, no. 3, pp. 492-505, 1926.

[45] N. Lu and W. J. Likos, "Suction stress characteristic curve for unsaturated soil," Journal of Geotechnical and Geoenvironmental Engineering, vol. 132, no. 2, pp. 131-142, 2006.

[46] A. Raveendiraraj, Coupling of mechanical behaviour and water retention behaviour in unsaturated soils [Ph.D. thesis], University of Glasgow, Glasgow, UK, 2009.

[47] M. Feng and D. G. Frelund, "Hysteresis influence associated with thermal conductivity sensor measurements," in Proceedings of the 52nd Canadian Geotechnical Conference and Unsaturated Soil Group, Proceeding from Theory to the Practice of Unsaturated Soil Mechanics, pp. 651-657, Regina, Canada, 1999.

[48] R. S. Sharma, Mechanical behavior of an unsaturated highly expansive clays [Ph.D. thesis], University of Oxford, Oxford, UK, 1998. 


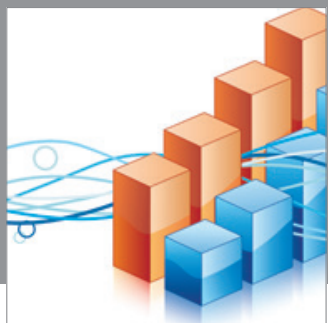

Advances in

Operations Research

mansans

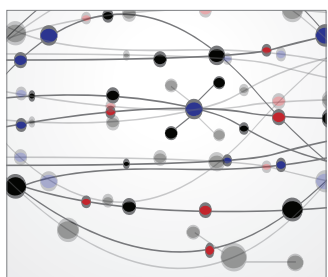

The Scientific World Journal
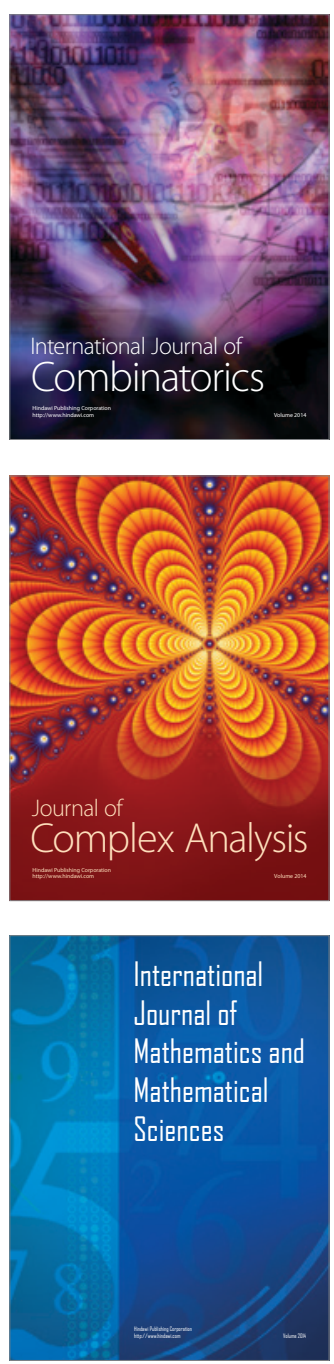
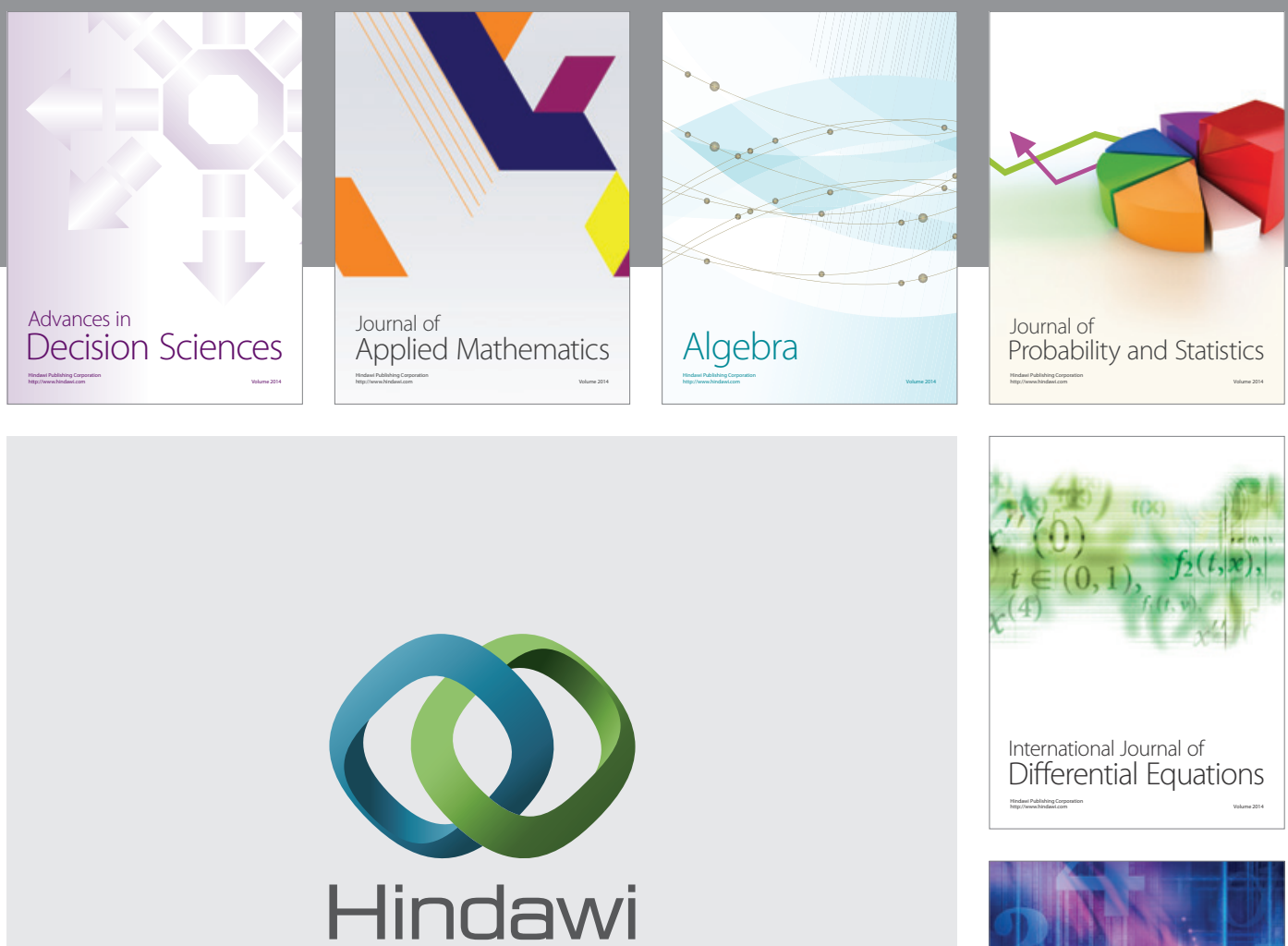

Submit your manuscripts at http://www.hindawi.com
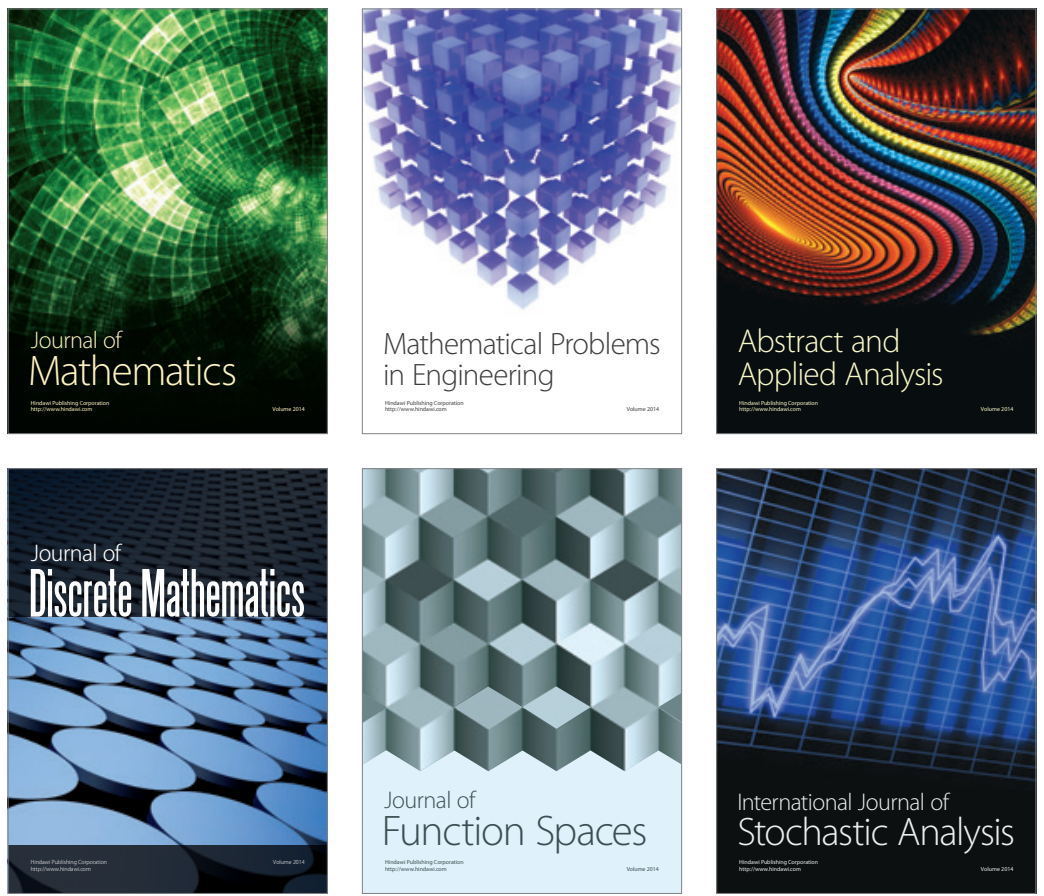

Journal of

Function Spaces

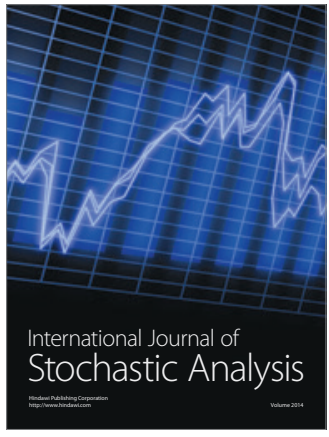

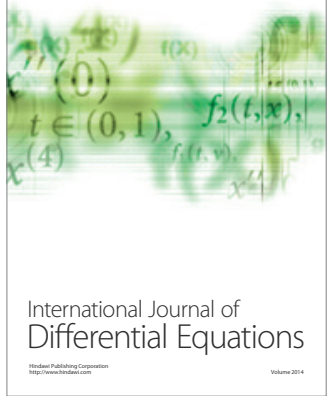
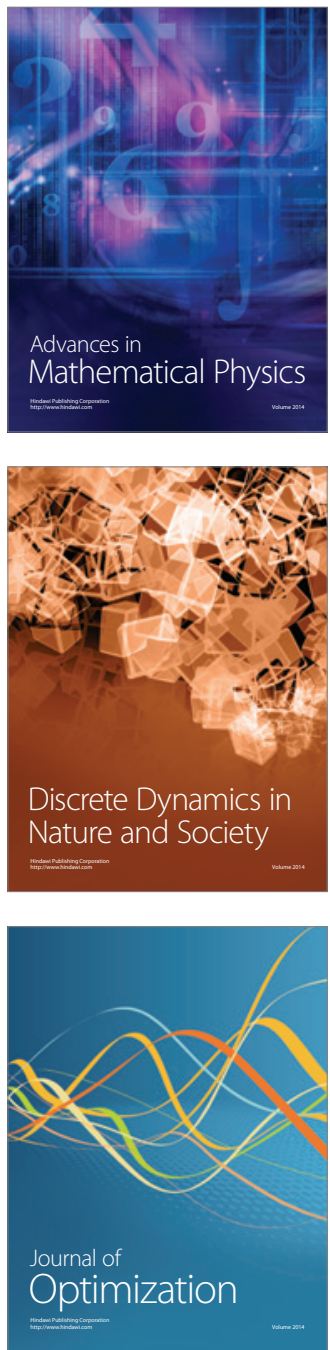